\title{
A review of the species of Anastatus Motschulsky (Hymenoptera: Chalcidoidea: Eupelmidae) of the Indian subcontinent
}

\section{T.C. Narendran}

Systematic Entomology Laboratory, Department of Zoology, University of Calicut, Calicut University P.O., Kerala 673635, India Email: drtcnarendran@yahoo.com

\begin{abstract}
The species of Anastatus Motschulsky (Chalcidoidea: Eupelmidae) from the Indian subcontinent are reviewed. A total of 28 species are recognized from the region based on females, including 13 species newly described from India. A key to females of the species is provided and figures illustrating differential features of 15 of the species included. Distribution and host data are provided where known. Anastatus dentatus Narayanan, Subba Rao \& Ramachandra Rao, 1960 is newly placed in synonymy with Anastatus ramakrishnai (Mani, 1935).
\end{abstract}

Keywords: Anastatus, Eupelmidae, Indian subcontinent, key, new species, review.

Date of online publication 26 February 2009 ISSN 0974-7907 (online) | 0974-7893 (print)

Editor: Gary Gibson

Manuscript details:

Ms \# 01903

Received 06 December 2007

Final revised received 11 October 2008

Finally accepted 26 November 2008

Citation: Narendran, T.C. (2009). A review of the species of Anastatus Motschulsky (Hymenoptera: Chalcidoidea: Eupelmidae) of the Indian subcontinent. Journal of Threatened Taxa 1(2): 72-96

Copyright: (C) T.C. Narendran 2009. Creative Commons Attribution 3.0 Unported License. JoTT allows unrestricted use of this article in any medium for non-profit purposes, reproduction and distribution by providing adequate credit to the authors and the source of publication.

Author Details: T.C. NARENDRAN is currently working as Emeritus Professor at the Systematic Entomology Laboratory of the Department of of Zoology, University of Calicut.

Acknowledgements: I thank the ministry of Environment and Forests, New Delhi for financial grant for a research project on Eupelmidae. I am grateful to the authorities of the University of Calicut for facilities. I have great pleasure in thanking Dr.Gary Gibson (Agriculture Canada) and Dr. M. Hayat, Aligarh Muslim University, Aligarh, India for critically reviewing my paper and Prof. Hayat for sending a collection of eupelmids for my study. The assistance given by my students $\mathrm{Mr}$. Abhilash Peter, Ms. Jilcy, M.C. and Ms. M. Sheeba is acknowledged. I thank Ms. Seena for helping in the photographic work. I have pleasure in thanking Dr. John S. Noyes of the Natural History Museum, London for taking the time to study some of the types of Anastatus present in the BMNH and supplying useful taxonomic information I requested.

OPEN ACGESS | FREE DOWNLOAD

\section{INTRODUCTION}

Most species of Anastatus Motschulsky (Eupelmidae: Eupelminae) are primary endoparasitoids of a wide variety of insect eggs of Blattaria, Homoptera, Hemiptera, Lepidoptera, Neuroptera, Mantodea, Orthoptera and Phasmidae. Some species are known to be hyperparasitoids of the eggs of Lepidoptera, larvae of Coleoptera, and puparia of Diptera (Gibson 1995). A few species have been used in biological control programmes against insect pests (Bouček 1988). Anastatus is a fairly large genus containing about 150 described world species. The Indian species of Anastatus were studied previously by Hayat (1975) and Mani (1989). Considering the importance of species as potential biocontrol agents of insect pests and the discovery of several new species in India it was necessary to update the taxonomic knowledge of this group, especially considering the more recent generic concepts of Eupelminae proposed by Gibson (1995). The subfamily Eupelminae is characterized by extreme sexual dimorphism and male eupelmines more closely resemble male Pteromalidae than female Eupelmidae (Gibson 1995). Because of this, the sexes are difficult to associate and taxonomy of the group has been based mostly on females, only females are included in this study. The purpose of the study is to describe several new species of Anastatus in the insect collection of the University of Calicut that were found in India and to provide a key to these and other species previously described from the Indian subcontinent, which include Bangladesh, Bhutan, India, Myanmar, Nepal, Pakistan and Sri Lanka.

\section{Materials AND Methods}

This review is based mainly on field-collected females. The specimens were curated and stored (card mounted) by methods described in Narendran (2001). Because paratypic material includes only females, the total number of paratypes is given and, where necessary, the number of specimens per collecting event in parenthesis following the collecting event data. Specimens were studied using a Leica MZ6 stereozoom microscope. Holotypes of newly described species are deposited in the Department of Zoology, University of Calicut, Kerala, India, pending transfer to National collection of Zoological Survey of India, Kolkata. The general style of description is adopted from various papers of Boucek and Gibson and many others. For the same reason separate scale is not given for each figures following the style of Bouček (1988), Gibson (1995) and many other international chalcidologists.

Type Depositories: DZUC - Department of Zoology, University of Calicut, Kerala, India; FRI - Forest Research Institute, Dehra Dun, India; IARI - Division of Entomology,

Abbreviations: $\mathrm{EH}$ - eye height; EW - eye width; F1 -F7 - funicular segments 1-7; IAA - interantennal area; LOL - lateral ocellar line (distance between anterior and posterior ocellus); L - length; LLM - lateral lobe of mesoscutum; MS - malar space; MG - malar groove; MLM - median lobe of mesoscutum; MV - marginal vein; OOL - ocellocular line (distance between posterior ocellus and inner margin of eye); POL - postocellar line (distance between posterior ocelli) ; SAC - scutellar axillar complex; SMV submarginal vein; STV - stigmal vein; T1 - T7 - metasomal tergites 1-7; W - width. 
Indian Agricultural Research Institute, New Delhi, India; MCNM - Instituto Eppanol de Entomologia, Museo Nacional du Ciencias, Naturales Madrid, Spain; MNHN - Museum National d' Histoire Naturelle, Laboratoire d' Entomologie Paris, France; SEA - School of Entomology, St.John's College, Agra, India; ZMMS - Moscow State University Museum, Moscow, Russia; ZSI - Zoological Survey of India, Kolkatta.

Anastatus Motschulsky

Anastatus Motschulsky, 1859: 116. Type species Anastatus mantoidae Motschulsky, by monotypy.

Cacotropia Motschulsky, 1863: 55. Type species Cacotropia echidna Motschulsky, by monotypy. Synonymy by Bouček, 1988. Antigaster Walsh and Riley, 1869: 156. Type species: Antigaster mirabilis Walsh and Riley, by monotypy. Synonymy by Ashmead, 1896.

Misocoris Rondani, 1877: 187. Type species: Misocoris oophagus Rondani. Subsequent designation and synonymy by 1974 .

Solindenia Cameron, 1883: 189. Type species: Solindenia picticornis Cameron, by monotypy. Synonymy by Swezey, 1946. Paraguaya Girault, 1911 [88]: 395-396. Type species: Paraguaya pulchripennis Girault, by monotypy and original designation. Synonymy by Girault, 1915.

Parooderella Girault, 1913 [175]: 88. Type species: Parooderella aptera Girault, by monotypy and original designation. Synonymy by Bouček, 1988.

Parasolindenia Girault, 1913 [175]: 90. Type species: Parasolindenia hemiptera Girault, by monotypy and original designation. Preoccupied by Parasolindenia Brues, 1907: 48. Synonymy by Bouček, 1988.

Pseudanastatus Masi, 1917: 162-163. Type speies: Pseudanastatus crassicornis Masi, by monotypy. Synonymy by Bouček, 1976.

Pseudooderella Brèthes, 1922: 127. Type species: Pseudooderella catamarcensi Brèthes, by monotypy. Synonymy by De Santis, 1960.

Cerycium Erdös, 1946: 137. Type species: Cerycium pratense Erdös, by monotypy and original designation. Synonymy by Erdos, 1960.

Vignalia Risbec, 195 1: 272. Type species: Vignalia halyomorphae Risbec (= Anastatus nezarae Risbec), by monotypy. Synonymy by Risbec, 1955.

Paravignalia Risbec, 1951: 274. Type species: Paravignalia hemipterae Risbec (= Anastatus aliberti Risbec), by monotypy. Synonymy by Risbec, 1955 .

Proanastatus De Santis, 1952: 267-268. Type species: Proanastatus excavatus De Santis, by monotypy and original designation. Synonymy by De Santis, 1980 (as subgenus).

Descampsia Risbec, 1955: 212-213. Type species: Descampsia dipterae Risbec, by monotypy. Synonymy by Gibson, 1995.

Anastatiomorpha Erdös, 1957: 363. Type species: Anastatimorpha siderea Erdös, by monotypy and original designation. Synonymy by Bouček, 1970 .

Anastatus (Cladanastatus) Boucek, 1979: 93-96. Type species: Anastatus (Cladanastatus) umae Bouček (= Oodera madagascariensis Risbec), by original designation.

Diagnosis: Female: Yellowish to brown or dark with varied metallic refringence; mesoepisternum sometimes partly white. Head subquadrate to distinctly wider than high; lower margin of toruli at or near lower ventral margin of eye; scrobal depression more or less bell shaped. Antennal formula 11173 [first flagellar segment considered here as anellus]. Mandibles bidentate, usually with small ventro-apical tooth and broad, truncate to slightly concave apical margin. Pronotum divided medially, subtriangular without distinct collar, usually concave postero-medially. Mesoscutum relatively flat or with distinct MLM and LLM; SAC varied but scutellum and axillae low, convex or flat. Propodeum with plical region narrow, often more or less bow tie-like, and below plane of abruptly inclined callar regions. Forewing macropterous or brachypterous; forewing of macropterous female highly varied in colour pattern but usually with brown to orange infumation and either with hyaline cross-band or spots below MV. Metasoma usually partly white basally, at least ventrally; T7 with posterior margin broadly rounded. (Diagnosis partly adapted from Gibson 1995.)

Male: Except for structure of mandibles, completely dissimilar to female (see Gibson, 1995).

Hosts: Primary parasitoids of eggs of Lepidoptera, Homoptera, Hemiptera, Blattaria, Orthoptera, Mantodea, Neuroptera and Phasmida. Some species can be hyperparasitoids of eggs of Lepidoptera through Scelionidae and Ichneumonoidea primary parasitoids and some have been reared from Coleoptera larvae and Diptera puparia (Gibson 1995).

Distribution: Cosmopolitan.

Subgenera: The genus Anastatus contains two subgenera: Anastatus Motschulsky and Cladanastatus Boucek. These two subgenera can be separated using the key given below.

Phylogenetics: Gibson (1995) dealt extensively with the phylogeny of Anastatus while dealing with the classification and phylogenetics of world Eupelminae. According to him, no autapomorphies are known to support the monophyly of Anastatus Motschulsky exclusive of Brasema Cameron and Zaischnopsis Ashmead. Character state distribution in the genera indicates that the three could form a successively paraphyletic assemblage.

\section{Anastatus (A.) Motschulsky 1. Anastatus (A.) absonus Narendran sp. nov.} (Figs. 1-2) (Image 1)

\section{Material examined:}

Holotype: Female, India: Kerala, Kollam Dt., Shasthamkottai, 9ㅇ' $\mathrm{N} \& 76^{\circ} 38^{\prime} \mathrm{E}, 12 . x \mathrm{ii} .2004$, coll. T.C. Narendran, DZUC \# MoEF 1649.

\section{Etymology}

The species name is taken from Latin meaning different.

\section{Description}

Female: Length $2.6 \mathrm{~mm}$.

Colour: Head metallic green; eye brown with margins around paler; ocelli reddish-brown; antenna pale yellow with F5-F7 and clava brown; pronotum pale brownish-yellow with rim of spiracle black; MLM metallic green with anterior marginal area and three longitudinal stripes oconnected to this part pale yellow; anterior half of LLM, tegula, prepectus and acropleuron pale brownish-yellow; concave area behind MLM, posterior half of LLM, and scutellar-axillar complex metallic green; propodeum dark brown; legs pale brownish-yellow; 


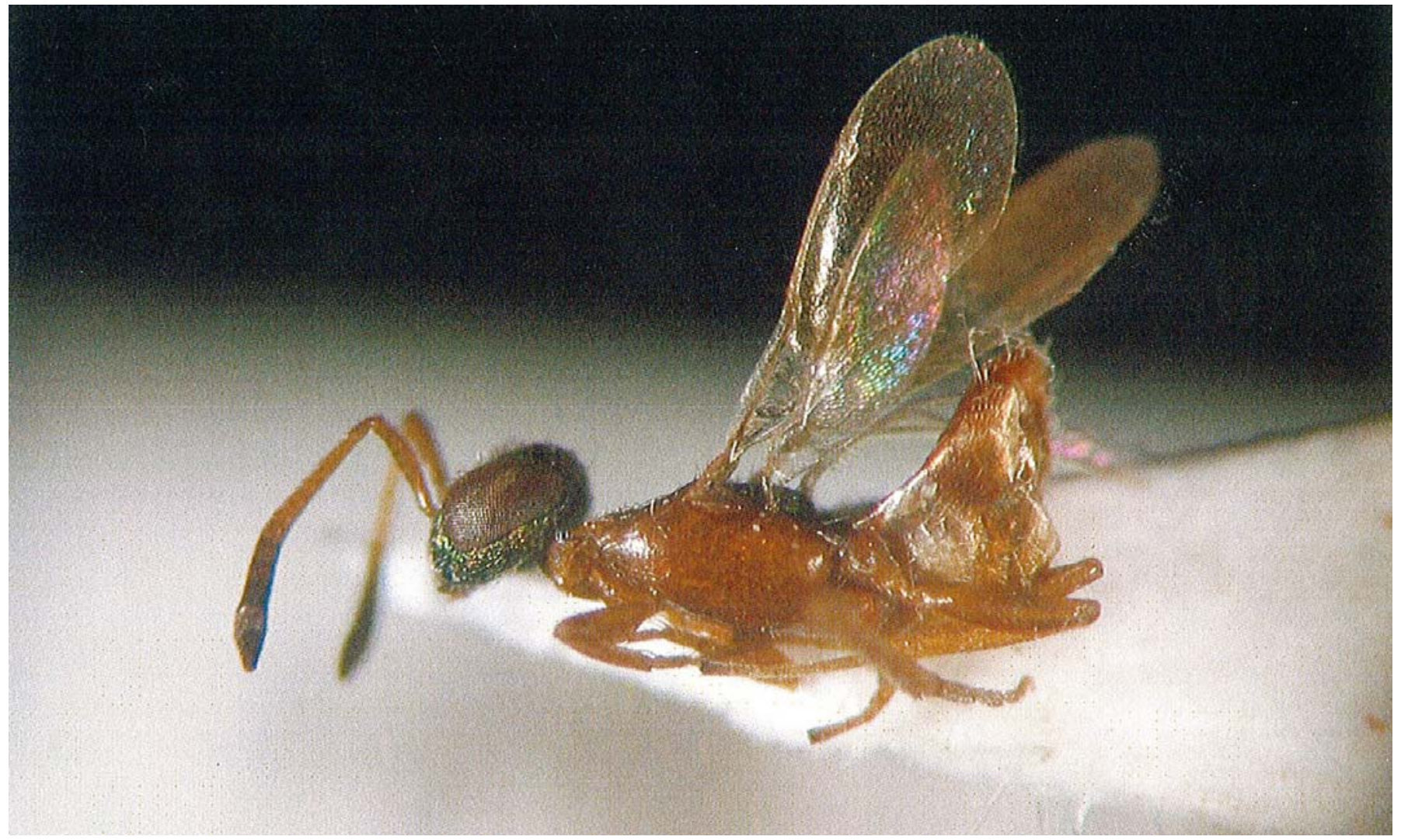

Image 1. Anastatus absonus Narendran sp. nov. Female: Profile

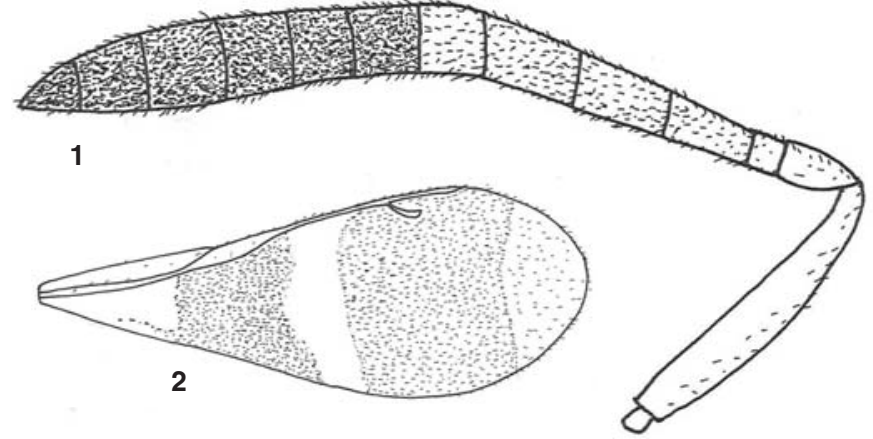

Figures 1-2. Anastatus absonus Narendran sp. nov. Female 1 - Antenna; 2 - Forewing

metasoma pale yellowish-brown with distal half of $\mathrm{T} 1$ and $\mathrm{T} 2$ pale yellow; forewing with pale brown infumation and hyaline band below MV, the distal margin straight and not reaching junction of MV and STV (Fig. 2); area behind SMV hyaline; apical part with infumation less pigmented and appears lighter.

Head: distinctly wider than high in anterior view (27:23); distinctly reticulate; OOL: POL: $\mathrm{LOL}=1: 3: 3$; frons, face, and gena with moderately dense white pubescence; IAA convex with a longitudinal ridge, well reticulate; scrobe deep, reticulate, lateral margins carinate, separated from front ocellus by a little more than diameter of front ocellus (4:3). Relative measurements of $\mathrm{L}: \mathrm{W}$ of antennal segments: scape $=37: 6$; pedicellus $=10: 5 ;$ anellus $=4: 4 ; \mathrm{F} 1=11: 5 ; \mathrm{F} 2=12: 7 ; \mathrm{F} 3=$ 12: $8 ; \mathrm{F} 4=8: 8 ; \mathrm{F} 5=8: 8 ; \mathrm{F} 6=7: 9 ; \mathrm{F} 7=8: 10 ;$ clava $=25: 10$.

Mesosoma: Pronotum with a median groove, concave posteriorly. Mesonotum with MLM longer than wide (11:8),
O.6 - 0.7x length of mesoscutum in dorsal view, well reticulate; mesoscutum with moderately dense pubescence; LLM well reticulate, almost flat, without raised dorsal margin (this is probably an artefact of preservation and it should be normally carinate). Prepectus subtriangular, faintly reticulate. Acropleuron longitudinally striate-reticulate. Macropterous; relative length of veins: $\mathrm{SMV}=47 ; \mathrm{MV}=38 ; \mathrm{PMV}=15 ; \mathrm{STV}$ $=7$. Midtibial spur shorter than mid basitarsus; midtarsus with a single row of pegs ventrally on either side on basal 4 segments; hind basitarsus a little shorter than combined length of following 3 tarsal segments.

Metasoma: A little longer than mesosoma (11: 10); T1 longest; T2 to T4 almost equal (subequal) in lenth; T5 shorter than T4; T4 broadest. Ovipositor sheath not exserted.

\section{Host: Unknown.}

\section{Remarks}

This species can be separated from all other Indian species in having antenna pale yellow with $\mathrm{F} 5$ to $\mathrm{F} 7$ and clava dark, hyaline band below MV without curved outer margin, MG straight, and MS $0.25 \mathrm{x} \mathrm{EH}$ in side view.

\section{Anastatus (A.) acherontiae Narayanan, Subba Rao \& Ramachandra Rao}

(Figs. 3-4)

Anastatus acherontiae Narayanan et al. 1960: 171, Female. Material examined India (Delhi) (IARI).

4 females, India: Himachal Pradesh, Hamirpur, Ammukalan, 1.vii.2006, coll. S.M. a. Badruddin \& F. Khan (1); Karnataka, 


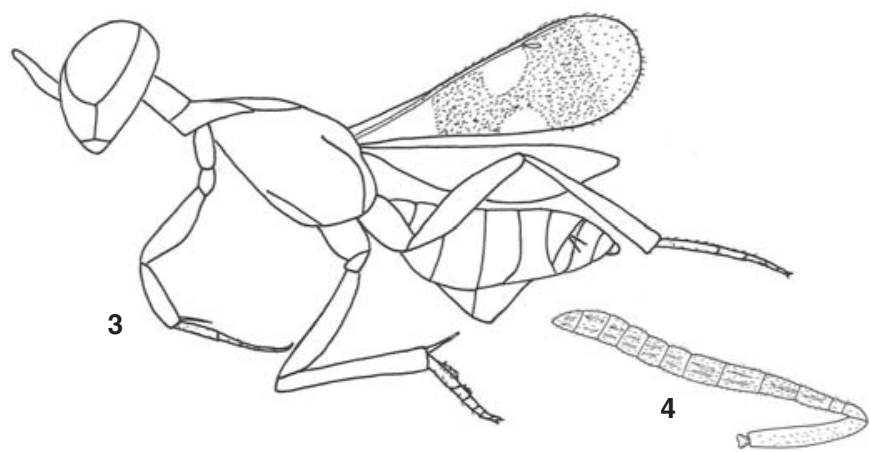

Figures 3-4. Anastatus acherotiae Narayanan et al. Female 1 - Body profile; 2 - Antenna

Nagarhole, $12^{\circ} 1^{\prime} \mathrm{N} \& 76^{\circ} 10^{\prime} \mathrm{E}, 16$. viii.2001, coll. P.A. Sinu (1); Kerala, Malappuram Dt., Calicut University Campus, $11^{\circ} 7^{\prime} \mathrm{N}$ \& 755'E, 2-5.xii.1988, 11.xi.1988, 29.i.1989, coll. K. Anil, 1.xii.1985, coll. T.C. Narendran \& Party (11); Kerala, Ernakulam 9.ii.1989, coll. T.C. Narendran \& Party (3); Kerala, Malappuram Dt., Kadakkattupara (near Calicut University), $11^{\circ} 7^{\prime} \mathrm{N} \& 75^{\circ} 5^{\prime} \mathrm{E}, 8 . i i .1988$ coll. Anil, K (1); Kerala, Malappuram Dt., Calicut University Campus, $11^{\circ} 7^{\prime} \mathrm{N} \& 75^{\circ} 5^{\prime} \mathrm{E}$, 2-5.xii.1988, 11.xi.1988, 29.i.1989, coll. K. Anil, 1.xii.1985, coll. T.C. Narendran \& Party (11); Kerala, Malappuram Dt., Nilambur $11^{\circ} 16^{\prime} \mathrm{N} \& 76^{\circ} 14^{\prime} \mathrm{E}$, 11.viii.1988, coll. T.C. Narendran \& Party (1); Kerala, Malappuram Dt., Karimpuzha, $10^{\circ} 46^{\prime} \mathrm{ON} \& 76^{\circ} 22^{\prime} 60 \mathrm{E}$, 13.xii. 1990 coll. K. Anil (1); 1.i.1986, coll. T.C. Narendran \& Party (1); Kerala, Palghat Dt., Malampuzha $10^{\circ} 53^{\prime} \mathrm{N} \& 76^{\circ} 46^{\prime} \mathrm{E}$, Kerala, Palghat Dt., Silent valley $11^{\circ} \mathrm{O} 4^{\prime} \mathrm{N} \& 76^{\circ} 79^{\prime} \mathrm{E}, 30 . x .1988$, coll. T.C. Narendran \& Party (1); Kerala, Thrissur Dt., Vazhani $10^{\circ} 38^{\prime} \mathrm{N} \& 76^{\circ} 19^{\prime} \mathrm{E}$, 8.ii.1989 coll. T.C. Narendran \& Party (1); Punjab, PKT, Dodhpur, Kulian, 11.vii.2006, coll. S.M.A. Badruddin (1); Tamil Nadu, Chennai (13 $\left.{ }^{\circ} 5^{\prime} \mathrm{N} \& 80^{\circ} 18^{\prime} \mathrm{E}\right)$, 2.viii.2003, coll. Paul Raj (eggs of Pentatomid bugs on weed) (1).

\section{Redescription}

Female: Length 2-3.1 mm.

Colour: Head metallic green or with metallic bronze with greenish refringence; antenna with scape pale brownish-yellow, remaining segments dark brown; pronotum pale brownishyellow; rim of spiracle black; MLM, LLM, area between lateral lobs beyond MLM, scutellar axillar complex, metanotum and propodeum with dark metallic green refringence; prepectus and acropleuron pale brown; foreleg with coxa pale brown, femur and tibia pale brownish-yellow, tarsus pale yellow; mid leg with coxa pale brownish-yellow, femur and tibia dark brown with base and apex pale yellow and tarsus pale yellow with dark pegs; hind leg with coxa dark brown, femur and tibia brown with base and apex of tibia paler, and tarsus pale yellow; gaster black with pale white or pale yellow at base. Forewing (Fig. 3) infumate with two hyaline spots or patches (one behind the other) behind MV, anterior hyaline spot reaching junction of MV and STV; base of wing hyaline, pigmentation on apex of forewing less pronounced.

Head: wider than high in anterior view, reticulate; IAA and ventral half of frons with moderately dense white pilosity; MS 0.36-0.37x EH in side view; MG straight; IAA broadly convex (weakly convex in some specimens), distinctly reticulate; area below IAA with moderately dense pubescence; scrobe reticulate, not deep, channel like, posteriorly shallow, lateral margins carinate, d separated from front ocellus slightly more than diameter of front ocellus, connected to front ocellus by a shallow narrow depression; OOL: POL: LOL $=1.5: 4: 2$ (in some specimens 1.5:4.5:2.2). Relative measurements of $\mathrm{L}: \mathrm{W}$ of antennal segments ; scape $=32: 6$; pedicel $=7: 4$; anellus $=4: 4$; $\mathrm{F} 1=10: 4 ; \mathrm{F} 2=10: 5 ; \mathrm{F} 3=11: 6 ; \mathrm{F} 4=10: 7 ; \mathrm{F} 5=7: 7 ; \mathrm{F} 6=7: 7$; $\mathrm{F} 7=6: 8$; clava $=20: 8$.

Mesosoma: Pronotum with distinct median groove, concave posteriomedially. Mesonotum with MLM distinctly longer than broad, 0.58-0.65x length of mesoscutum in dorsal view, a little convex, distinctly reticulate-punctate; LLM faintly reticulate, mostly shiny, dorsal margin posteriorly raised sharply; area beyond MLM and between LLM shallowly concave, smooth and shiny with sparse pubescence; SAC similarly sculptured as on MLM; scutellum convex. Prepectus subtriangular, smooth. Acropleuron finely sculptured. Macropterous; relative lengths of veins: $\mathrm{SMV}=45 ; \mathrm{MV}=51 ; \mathrm{PMV}=15, \mathrm{STV}=6$. Mid tibial spur almost equal to mid mid metatarsus, mid tarsus with a single row of dark pegs ventrally on either side on basal 3 tarsal segments; hind basitarsus as long as following 3 segments combined.

Metasoma: As long as mesosoma; T1 longer than T2, its hind margin deeply incised medially; T2 longer than T3, its hind margin medially incised; $\mathrm{T} 4$ almost equal in length of T3; T5 with posterior margin broadly concave; T6 with posterior margin convex.

Variation: Provided in the above rescription.

\section{Host}

Acherontia styx (Westwood) (Lepidoptera: Sphingidae) (Narayan et al. 1960; Pentatomidae (Hemiptera) egg (New record for Pentatomidae).

\section{Distribution:}

India (Delhi, Punjab. New recods: Kerala, Himachal Pradesh, Tamil Nadu). Probably wide spread all over India

\section{Remarks}

A.acherontiae comes near $A$. mohanae in general appearance but differs from $A$. mohanae in having: hyaline patch below MV extend to junction of MV and STV, LLM with dark metallic green refringence, acropleuron without longitudinal striae, mid tibial spur almost equal in length to midbasitarsus, and hind basitarsus as long as following three segments combined. Besides these differences the proportions of antennal segments, metasomal tergites and forewing veins differ in both species.

\section{Anastatus (A.) alaredactus Narendran sp. nov.}

(Figs. 5-9)

\section{Material examined}

Holotype: Female, India: Kerala, Thrissur Dt., Agricultural University $10^{\circ} 28^{\prime} \mathrm{N} \& 76^{\circ} 18^{\prime} \mathrm{E}, 15 . x .1988$, coll. T.C. Narendran \& Party, DZUC \# MoEF 1641.

Paratypes: 1 female, India: Kerala, Malappuram Dt., Calicut University Campus $11^{\circ} 7^{\prime} \mathrm{N} \& 75^{\circ} 5^{\prime} \mathrm{E}$, and 04.ii.1988, coll. T.C. Narendran \& Party.

\section{Etymology}

The species name is formed from the Latin words 'ala' 


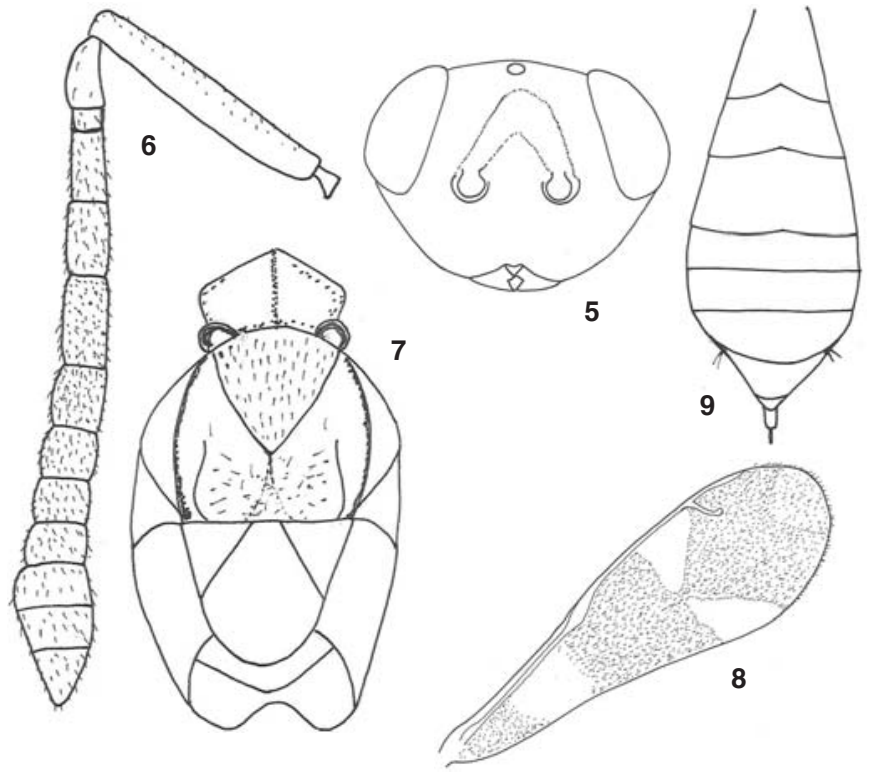

Figures 5-9. Anastatus alaredactus Narendran sp. nov. Female

5 - Head front view; 6 - Antenna; 7 - Mesosoma dorsal view;

8 - Forewing; 9 - Metasoma dorsal view

meaning wing and 'redactus' meaning short.

\section{Description}

Holotype Female: Length $2.1 \mathrm{~mm}$.

Colour: Yellow except as follows: eye gray with black spot medially; antennal flagellum and pedicel brown, darker towards clava; metasoma with yellowish-white band on T1 and T2, beyond T2 black except ovipositor sheath yellow. Forewing pale brownish-yellow, infumate with three hyaline patches: one below SMV and other two below MV (one below the other) (Fig.16), apex of forewing slightly less infumate.

Head: Wider than high in anterior view (78: 59), reticulate; lower face with short, sparse yellow pubescence; MS 0.67x EH in side view; MG straight; IAA convex, micropunctate; scrobe shallow, lateral margin weakly carinate, separated from front ocellus by diameter of front ocellus; scrobe reticulate; OOL: POL: $\mathrm{LOL}=3: 3: 1.5$. Relative measurements of $\mathrm{L}: \mathrm{W}$ of antennal segments: scape $=44: 7$; pedicel $=10: 6$; anellus $=5: 3$; $\mathrm{F} 1=11: 5.5 ; \mathrm{F} 2=12: 7 ; \mathrm{F} 3=15: 7 ; \mathrm{F} 4=10: 8 ; \mathrm{F} 5=8: 9 ; \mathrm{F} 6=$ $7: 9 ; \mathrm{F} 7=6: 10 ;$ clava $=24: 12$.

Mesosoma: Pronotum with a median line of weak sclerotization, shallowly concave posteromedially. Mesoscutum with MLM only slightly convex, weakly reticulate punctate, $0.66 \mathrm{x}$ dorsal length of mesoscutum; LLM, weakly reticulate with sharp dorsal margin on posterior half; interspace between lateral lobes behind MLM deeply concave, weakly sculptured, mostly smooth and shiny; mesoscutum moderately pubescent (Fig. 7); scutellar axillar complex weakly reticulate, scutellum slightly convex, apex rounded. Propodeum without median carina. Prepectus subtriangular, mostly smooth. Acropleuron with strong longitudinal sulci. Brachypterous, forewing not reaching apex of gaster but exceeding middle of gaster; relative length of veins: $\mathrm{SMV}=47, \mathrm{MV}=41, \mathrm{PMV}=16, \mathrm{STV}$ $=8$. Midtibial spur slightly shorter than basitarsus; mid tarsus with single row of dark pegs on either side ventrally on basal four segments; hind basitarsus as long as following three segments combined.

Metasoma: Longer than mesosoma (26:20), gradually widening upto T6. T1 longer than T2, T3 longer than T1; T4 about half as long as T3; T5 as long as T4; T6 longer than T4. Variation: Length varies from 2.1-2.2 mm. In paratype metasoma blacker without metallic tinge.

\section{Host: Unknown.}

\section{Remarks:}

This is a unique species with head, mesosoma and legs yellow and metasoma black with $\mathrm{T} 1$ and T2 yellowish-white. It comes near $A$. ochirosis in the yellow colour of body but differs from $A$. ochirasis in having: forewing not reaching apex of gaster, forewing without a hyaline band but with two hyaline patches below MV; gaster beyond $\mathrm{T} 2$ black and antenna with different colour pattern.

\section{Anastatus (A.) amarus (Subba Rao)}

Solindenia amara Subba Rao, 1957: B. 46: 376, Male and Female (holotype), India, New Delhi (IARI).

Anastatus amarus (Subba Rao); Narayanan, Subba Rao and Ramachandra Rao, 1960: 175.

Anastatus acherontiae: Hayat, 1975: 266. Female (misidentification?)

\section{Material examined}

5 females, India: Uttar Pradesh, Aligarh, $27^{\circ} 54^{\prime} \mathrm{N} \& 78^{\circ} 4^{\prime} \mathrm{E}$, 13.viii.1983, coll. S. Islam (1); same collection data except date 3.viii.1983, 23.viii.1983, 24.viii.1983, 26.iii.1984 (4).

\section{Distribution}

India (New Delhi \& Ranchi)

\section{Diagnosis}

Female: Length $3.30 \mathrm{~mm}$.

Colour: Head metallic with blue green iridescence and coppery lustre at certain angles, antenna dark brown with pedicel brilliant metallic green, scape lemon yellow; mesosoma dark brown with deep bluish-violet refringence on MLM; axillae bronzy and scutellum with metallic purple refringence; foreleg with coxa pale brown, femur and tibia pale brownishyellow, tarsus pale yellow; mid leg with coxa pale brownishyellow, femur and tibia dark brown with base and apex pale yellow and tarsus pale yellow with dark pegs; hind leg with coxa dark brown, femur and tibia brown with base and apex of tibia paler, and tarsus pale yellow Forewing infumate with two hyaline spots or patches (one behind the other) behind MV, anterior hyaline spot reaching junction of MV and STV; base of wing hyaline, pigmentation on apex of forewing less pronounced.

Head: wider than long in anterior view, reticulate; IAA and ventral half of frons with moderately dense pilosity ; MS 0.31043x EH in side view; MG slightly bend at middle towards posterior part; IAA convex, distinctly reticulate; scrobe moderately deep, channel like, posteriorly shallow, reticulate, lateral margins carinate, separated from front ocellus by a distance a little more than diameter of front ocellus, connected to front ocellus by a shallow groove. OOL:POL:LOL= 1:4:2. Relative leasurements of L:W of antennal segments: scape= $25: 4 ;$ pedicel $=5: 3 ;$ anellus $=2: 3 ; \mathrm{F} 1=4: 3 ; \mathrm{F} 2=7: 3.5 ; \mathrm{F} 3=6: 4$; 
$\mathrm{F} 4=6: 5 ; \mathrm{F} 5=5: 5 ; \mathrm{F} 6=5: 5 ; \mathrm{F} 7=5: 5 ;$ clava $=11: 5$.

Mesosoma: Pronotum with distinct median groove, concave posteriormedially. Mesonotum with MLM distinctly longer than broad, 0.54-0.64x length of mesoscutum in dorsal view, convex with raised close reticulation and punctate; LLM faintly reticulate, mostly shiny; dorsal margin posteriorly raised sharply, area beyond MLM and between LLM concave, smooth and shiny with moderately dense pubescence; SAC similarly sculptured as MLM; scutellum convex. Prepectus subtriangular, smooth and shiny. Acropleuron finely striatereticulate. Macropterous, relative lengths of forewing veins: $\mathrm{SMV}=32 ; \mathrm{MV}=44 ; \mathrm{PMV}=17 ; \mathrm{STV}=7$. Midtibial spur equal or a little longer than midbasitarsus; midtarsus with a row of dark pegs on either side ventrally on basal three tarsal segments; hindbasitarsus as long as (or slightly longer) following two segments combined.

Metasoma: longer than mesosoma; T1 longest, its posterior margin slightly sinuate at middle; T2 shorter than T3; T4 almost equal in length of T3; T5 almost equal or a little shorter than T4; T6 with posterior margin convex. T4 and T5 broader than others.

Male: Similar to female but smaller. (Eventhough this was stated in the original description,it cannot be so. It is possible that SubbaRao mistook a small female for male, but in any event it was not included in the type material of the species. Gibson 2008 pers. comm.).

\section{Host}

Apanteles delhiensis Subba Rao (Hymenoptera: Braconidae) parasitic on Hymenia recurvalis (Linn.) (Lepidoptera: Pyralidae) and Tessaratoma javanica Thumb (Hemiptera: Pentatomidae) (Subba Rao 1957; Mehra 1966).

\section{Remarks}

Females of $A$. amarus are very similar to $A$. acherontiae but can be separated by the characters used in the key above. It is possible that $A$. amarus and $A$. acherontiae may be sibling species. The status of these species can be determined only by studying more specimens of amarus and acherontiae from the localities of the relevant types.

\section{Anastatus (A.) bangalorensis Mani \& Kurian}

(Figs. 10-11)

Anastatus bangalorensis Mani \& Kurian, 1953: 13, Female, India, Bangalore (SEA?).

\section{Material examined}

3 females, India, Karnataka, Koorlugaya, 26.ix.2001, coll. M. Daniel (1); Kerala, Kannur Dist, T.C. Narendran 12.iii.2007 (1); Kerala, Wayanad, 10.iv.2006 T.C. Narendran (1).

\section{Drtibution}

India (Bangalore, Kerala (new record for Kerala))

\section{Diagnosis}

Female: Length $2.50-2.60 \mathrm{~mm}$.

Colour: Head dark with metallic green refringence (in some specimen head a ittle more metallic green), antennal flagellum and pedicel brown or black; scape pale yellow or pale brownishyellow; mesosoma dark brown with metallic green or greenishblue refringence on posterior part of MLM and on lateral lobes

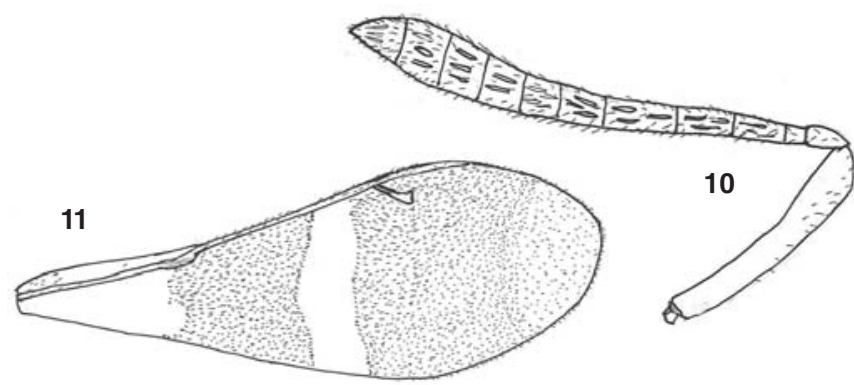

Figures 10-11. Anastatus bangalorensis Mani \& Kurian. Female

10 - Antenna; 11 - Forewing

(in specimen from Kannur dt. green refreingence on mesoscutum weak and in specimen from Wayanad dt. it is well pronounced); acropleuron reddish-brown or darker; gaster dark brown with base pale white; legs brown with mid tibial spur and tarsus pale yellow. Forewing infumate with basal part behind SMV and crossband behind MV hyaline, hyaline band amost straignt outer margin, not extending upto junction of MV and STV; apical part of forewing with weaker infumation (Fig. 11).

Head: 1.20-1.31x wider than high in front view, distinctly reticulate, IAA and ventral half of frons with moderately dense white pubescence; MS 0.38-0.41x EH in side view; MG straight; IAA broadly convex, distinctly reticulate; scrobe not deep, posteriorly shallow, lateral margin carinate; scrobe separated from front ocellus by a distance equal to diameter of front ocellus, connected to front ocellus by a shallow groove like depression; scrobe strongly reticulate; OOL: POL: LOL = 1:5:2.5. Relative measurements of $\mathrm{L} ; \mathrm{W}$ of antennal segments: scape $=33: 5$; pedicel $=6: 3$; anellus $=3: 2 ; \mathrm{F} 1=7: 3 ; \mathrm{F} 2=8: 3$; $\mathrm{F} 3=10: 4 ; \mathrm{F} 4=6: 5 ; \mathrm{F} 5=5: 5 ; \mathrm{F} 6=6: 6 ; \mathrm{F} 7==6: 8 ;$ clava $=19: 8$.

Mesosoma: Pronotum with distinct median groove; concave posteriormedially; MLM longer than broad, about 0.60x length of mesoscutum in dorsal view, a little convex, distinctly reticulate punctate; LLM weakly reticulate, mostly shiny, dorsal margin posteriorly raised; area beyond MLM and between LLM shallowly concave, smooth and shiny, with sparse pubescence (or no pubescence in one specimen); SAC strongly sculptured; scutellum convex. Prepectus subtriangular, faintly reticulate. Acropleuron distinctly striate-reticulate. Macropterous; relative lengths of veins: $\mathrm{SMV}=39 ; \mathrm{MV}=39 ; \mathrm{PMV}=19$; $\mathrm{STV}=9$. Mid tibial spur almost equal in length to midbasitarsus; midtarsus with a single row of dark pegs on either side ventrally on basal 3 tarsal segments (on fourth tarsal segment a pair of relatively smaller peg at distal end); hindbasitarsus a little longer than following two segments combined.

Metasoma: distinctly longer than mesosoma; T1 longest, its posterior margin not clearly sinuate at middle; T2 shorter than T3; T4 shorter than T3; T5 a little longer than T4; T1 to T5 becoming broader and T5 broadest. Ovipositor sheath slightly visible from dorsal side.

Male: Unknown.

\section{Host}

Eggs of Halymorpha marmorea F. (Heteroptera: Pentatomidae New record). Eggs of pentatomid bugs on Pongamia glabra Vent.Sans (Fabceae) (Mani \& Kurian 1953). 


\section{Remarks}

$A$. absonus resembles $A$. bangalorensis in general features but differs from it in having F1 to F4 pale brownish-yellow; MLM metallic green with posterior marginal area and three longitudinal strips pale yellow and forewing with weaker infumation.

\section{Anastatus (A.) bifasciatus (Geoffroy)}

(Fig. 12)

Cynips bifasciatus Geoffroy, 1785: 388. Female, France (MNHN). Cinips bifasciata Fonscolombe, 1832. Female, France (OXUM). Synonymy by Bouček, 1970: 80 .

Cinips Bombycum Fonscolombe, 1832: 295. Male, France (lost). Synonymy by Graham, 1992: 1101.

Eupelmus bifasciatus (Geoffroy); Forster, 1860: 122.

Pteromalus Oomyzus Rondani, 1872: 202. Male, Italy (MZUF). Synonymy by Bouček, 1974: 261.

Pteromalus ovivorus Rondani, 1872: 203. Female, Italy (MZUF). Synonymy by Bouček, 1974: 262.

Misocoris oophagus Rondani, 1877: 187. Male, Italy (MZUF). Synonymy by Bouček, 1974: 262.

Diplolepis bifasciata (Geoffroy); Dalla Torre, 1898: 418.

Eupelmus subaeneus De Stephani, 1898: 251. Female, Italy. Synonymy by Bouček, 1970: 80.

Anastatus eurycephalus Masi, 1919: 321. Female, Italy (MCSN, BMNH). Synonymy by Bouček, 1970: 80.

Cerycium pratense Erdos, 1946: 138. Male, Hungary (lectotype designated by Thuroczy, 1992, HNHM). Synonymy by Bouèek, 1970: 80 .

\section{Material examined: None.}

\section{Distribution}

Widely distributed in Europe, Africa, and Asia. Masoodi et al. (1986) reported it from India though Hayat (1975) stated that reports of this species from India need confirmation.

\section{Diagnosis}

(based on Ferriere, 1930, Nikolskaya, 1960, Tryapitzin 1987 and Bouček, 1970)

Female: Length 2.4-3.3mm.

Body dark violet with golden green lustre in some places; scutellum and axillae bronze; scape yellowish-brown; legs dark brown; part of T 1 and T2 pale or translucent (in some specimens T2 not distinctly whitish at the end but only slightly paler); head $3.3 \mathrm{x}$ as broad as long in dorsal view (in some specimens mesosoma more greenish without violet refringence but vertex,

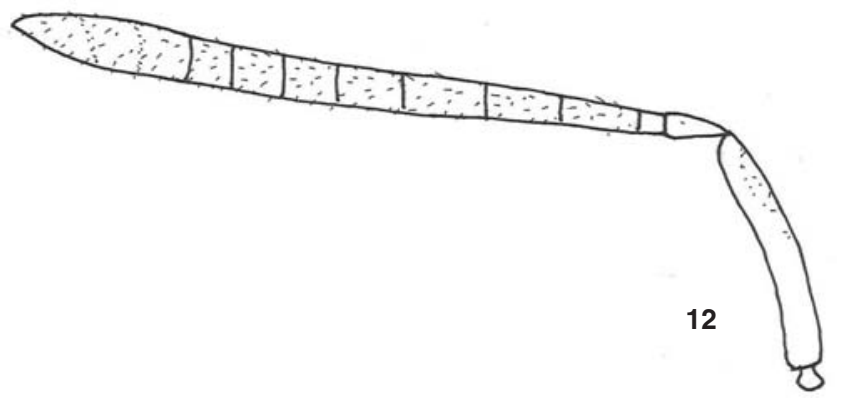

Figure 12. Anastatus bifasciatus (Geoffroy). Female 12 - Antenna scutellum, axillae and metasoma also without bronze colour); antenna as in figure 1c of Ferriere 1930 and Fig. 477 of Nikolskaya (1960); forewing infumate with a transverse hyaline band curved in the middle, slightly narrowed towards posterior margin; apical part of forewing slightly lighter; basal part below SMV not infumate; MLM about $0.8 \mathrm{x}$ length of mesoscutum; midtibial spur a little shorter than mid basitarsus; metasoma a little longer than mesosoma (33:36).

Host

This species attack a wide variety of hosts viz. Hemiptera (Aphididae, Coreidae, Pentatomidae, Psyllidae, Scutelleridae), Lepidoptera (Lasiocampidae, Lymantridae, Notodontidae, Nymphalidae, Papilionidae, Saturniidae, Sphingidae), Orthoptera (Acrididae, Tettigonidae) and Hymenoptera (Braconidae). For detailed list see Noyes (2003).

\section{Remarks}

A. bifasciatus comes near A.phaeonotus in general features but differs from A. phaeonotus in having MLM 0.7 or more as long as mesoscutum, metasoma $1.5-1.6 \mathrm{x}$ as long as broad, scape $5.33 \mathrm{x}$ as long as pedicel head in dorsal view $3.3 \mathrm{x}$ as broad as long and MLM dark with metallic green refringence.

\section{Anastatus (A.) colemani (Crawford)}

Anastatus colemani Crawford, 1912: 42:6. Female (syntypes) India, Bangalore (USNM).

Matarial examined: None.

\section{Distribution}

India (Karnataka, Tamil Nadu, Bihar, Uttapradesh), Malaysia, Taiwan (Noyes 2003)

\section{Diagnosis (based on Mani 1989)}

Female: Length $3.50 \mathrm{~mm}$. Head green; face metallic red; MLM bronzy; other parts of mesonotum with bluish green refringence; scutellum bronzy; rest of mesosoma and legs bronzy or purple; metasoma aeneous with a white transverse band near hind margin of T1; scape testaceous; pedicel green, basal funicular segments aeneous; F1 about 2x as long as pedicel and about as long as clava; F2 to F5 gradually becoming shorter; F6 and F7 subquadrate, MLM and LLM finely reticulate with shallow close punctae behind; SAC umbilicately punctate; acropleuron finely striate; forewing hyaline basally, and with a curved hyaline band in the middle of vein MV; SMV about equal to MV; PMV about 0.50 of MV; STV shorter than 0.50 of PMV. Metasoma short.

Male: Unknown.

\section{Hosts}

Pentatomidae [Degonatus serratus Dist., Placosternum dama (Fabricius), Rhynchocoris humeralis (Thunberg), Tessaratoma javanica (Thunberg), Tetroda histeroides (Fabricius)], Saturnidae [Attacus atlas L.]. (Noyes 2003 listed these based on several authors).

\section{Remarks}

It is difficult to identify this species from the short available description. However, the metallic red face, bronzy MLM, scutellum, legs; F1 about 2x as long as pedicel and as long as 
clava and SMV almost equal to MV are features which may help to identify this species along with the key provided above in this work.

\section{Anastatus (A.) cuspidiatus Narendran sp. nov.} (Figs. 13-16)

\section{Material examined}

Holotype: Female, India: Kerala, Palghat Dt., Malampuzha $10^{\circ} 53^{\prime} \mathrm{N} 76^{\circ} 46^{\prime} \mathrm{E}, 11 . x \mathrm{ii} .1987$, coll. T.C. Narendran \& Party DZUC \# MoEF 1639.

Paratypes: 7 females, India: Kerala, Malappuram Dt., Calicut University Campus, $11^{\circ} 7^{\prime} \mathrm{N} \& 75^{\circ} 5^{\prime} \mathrm{E}, 12$. iii.1985, coll. T.C. Narendran; Kerala, Thrissur Dt., Peechi, $10^{\circ} 31^{\prime} \mathrm{N} \& 76^{\circ} 13^{\prime} \mathrm{E}$, 5.ii.1989, coll. T.C. Narendran \& Party; Uttar Pradesh, Aligarh, $27^{\circ} 54^{\prime} \mathrm{N} \& 78^{\circ} 4$ 'E, 22.viii.1979, coll. M. Hayat; Uttar Pradesh, Aligarh, 27 $54^{\prime} \mathrm{N} \& 78^{\circ} 4^{\prime} \mathrm{E}$, 22.viii.1979, coll. M. Verma; West Bengal, Sadhanapur, $24^{\circ} 31^{\prime} \mathrm{N} \& 88^{\circ} 45^{\prime} \mathrm{E}$, 23.ix.1983, coll. S.S. Islam; Kerala, Malappuram Dt. Edayur, $10^{\circ} 56^{\prime} \mathrm{N} \& 76^{\circ} 6^{\prime} \mathrm{E}$, 1.x.1988, coll. T.C. Narendran \& Party; Uttar Pradesh, Sodabad, Bidai, $27^{\circ} 27^{\prime} \mathrm{N} \& 78^{\circ} 2^{\prime} \mathrm{E}, 4 . i x .2006$, coll. M. Hayat \& F.R. Khan.

\section{Etymology}

The species name is formed from the Latin word 'cuspis' meaning pointed, indicating a pointed gaster.

\section{Description}

Holotype: Female: Length 3.4mm.

Colour: Brownish-black; head with slight bronze and metallic green refringence; eyes dark brown with pale gray borders; ocelli pale reflecting yellow; pronotum dull brownishyellow with posterior corners including spiracular borders brownish-black with slight metalic green refringence; remaining part of mesosoma black with metallic green refringence; legs dark brown with midtibial spur and midtarsal segments pale yellow, except black pegs on midtarsal segments and apex of midtibia; metasoma black with T2, apex of gaster,

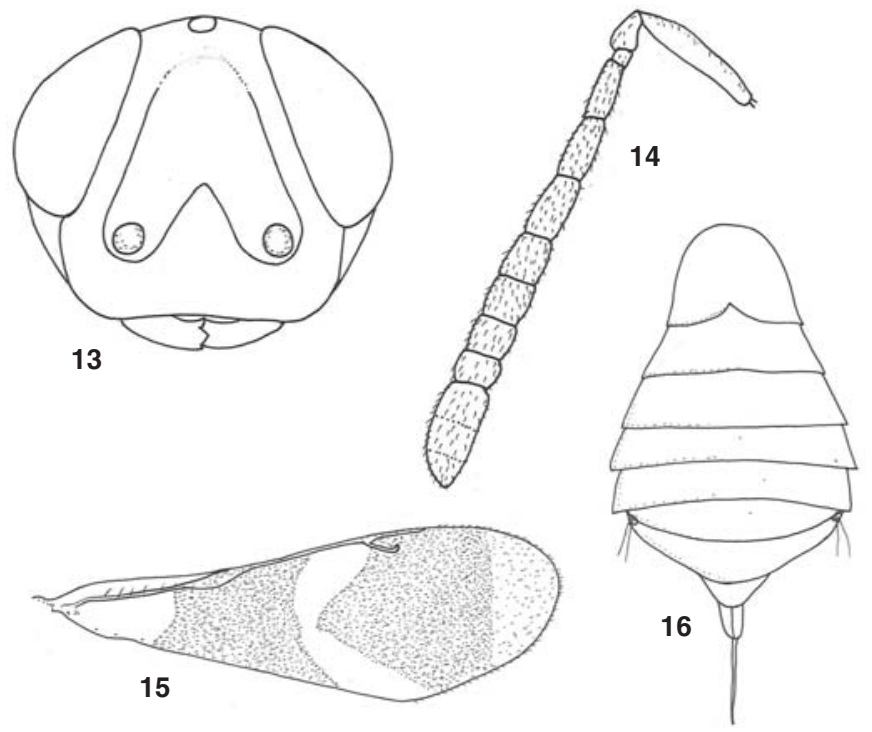

Figures 13-16. Anastatus cuspidiatus Narendran sp. nov. Female

13 - Head front view; 14 - Antenna; 15 - Forewing; 16 - Metasoma dorsal view apex of ovipositor sheath and ovipositor pale yellow. Forewing infumated with median transverse hyaline band, the bandreaching junction of $\mathrm{MV}$ and $\mathrm{STV}$ and with outer margin strongly angulate (Fig. 15).

Head: Wider than high in anterior view (72:64), reticulate; lower face with scattered white short pubescence; MS $0.38 \mathrm{x}$ EH in side view; MG straight; IAA convex, scrobe not deep posteriorly; lateral margins carinate; scrobe separated from front ocellus by diameter of front ocellus; scrobe reticulate; IAA and lower face coriaceous; OOL: POL: LOL $=2: 5: 3$. Relative measurements of L:W of antennal segments : scape $=27: 5$, pedicel $=8: 5$, anellus $=3: 3, \mathrm{~F} 1=11: 5, \mathrm{~F} 2=12: 5, \mathrm{~F} 3=13: 7$, $\mathrm{F} 4=9: 8, \mathrm{~F} 5=8: 8, \mathrm{~F} 6=7: 8, \mathrm{~F} 7=5: 8$, clava $=20: 9$.

Mesosoma: Pronotum bare dorsally, weakly reticulate, medially divided by a weak longitudinal median line, medially depressed. Mesonotum with MLM densely reticulate punctate, $0.58 \mathrm{x}$ dorsal length of mesoscutum; LLM less strongly reticulate with sides and posterior part smooth and shiny, with raised dorsal edge on posterior half; interspace between lateral lobes behind MLM deeply concave, faintly reticulate medially; mesoscutum with scattered white setae medially, mostly bare on sides; scutellar axillar complex reticulate punctate; axillae broadly separated anteromedially; scutellum distinctly convex, apex rounded. Propodeum with plical region narrow, without median carina, separated from callar region by plical furrow, posterior margin deeply concave. Prepectus subtriangular, faintly reticulate. Acropleuron longitudinally striate and not at all faint as in donius. Macropterous; relative length of veins: $\mathrm{SMV}=45 ; \mathrm{MV}=39 ; \mathrm{PMV}=15 ; \mathrm{STV}=8$. Midtibial spur subequal to basitarsus, with a single row of black pegs ventrally on either side on basal three segments of mid tarsus; hind basitarsus as long as following three segments combined.

Metasoma: A little longer than mesosoma (23:20); T1 longer than T2, its posterior margin medially incised; width gradually increasing from $\mathrm{T} 1$ to $\mathrm{T} 4$ or $\mathrm{T} 5$; $\mathrm{T} 6$ narrower than $\mathrm{T} 5$. T3 longer than T4; T5 a little longer than T4. Ovipositor sheath about $0.10 \mathrm{x}$ as long as gaster.

Variation: Length varies from $3.13-3.5 \mathrm{~mm}$. In specimens from northern India frontovertx with purple and gena with bluish-violet refringence. POL varies from 3.5 to $3.8 \mathrm{x}$ OOL.

Host: Unknown.

\section{Remarks}

This new species comes near A.operosus sp. nov. in general appearance but differs from it in having: F1 and F2 distinctly longer than pedicel, clava shorter than scape and acropleuron longitudinally striate.

\section{Anastatus (A.) dasyni Ferrière (Fig. 17)}

Anastatus dasyni Ferrière, 1935: 146.Female Malaya, Sudang $(\mathrm{BMNH})$.

\section{Material examined}

4 females, India: Kerala, Thiruvananthapuram, Vellayani, $08^{\circ} 50^{\prime} \mathrm{N} \& 76^{\circ} 9^{\prime} \mathrm{E}, 7.11 .2005$, coll. M.H. Faizal.

\section{Distribution}

Africa. India (Kerala). This is the first record of this species from Indian subcontinent. 


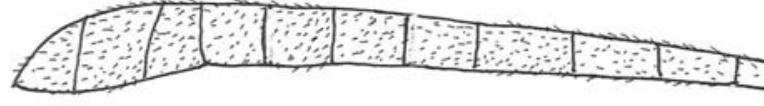

17

Fig. 17. Anastatus dasyni Ferriere

17 - Antenna

\section{Diagnosis}

Female: Length 2-2.3mm.

Colour: Head with dark metallic green and purple refringence; mesoscutum and scutellum with dark bluish-green refringence; gaster black with base pale yellow; legs brown with some parts slightly darker, mid tarsus pale brown. Antenna as in figure 63; forewing with distal margin of hyaline band curved (not distinctly angulated); infuscated from area behind parastigma to apex with apical part a little less pigmented, appearing light.

Head: a little wider than high in anterior view, reticulate; IAA and ventral half of frons coarsely reticulate and with moderately dense white pubescence. MS 0.31-0.33x EH; MG curved posteriorly at its middle; IAA convex, with raised reticulation; scrobe, shallow, channel like, reticulate, lateral margins weakly carinate; scrobe separated from front ocellus by $2.5-3 \mathrm{x}$ diameter of front ocellus. OOL: POL:LOL $=1: 4: 2$. Relative L:W of antennal segments: scape $=39: 5$; pedicel $=8: 4$; anellus $=4: 3 ; \mathrm{F} 1=9: 4 ; \mathrm{F} 2=9: 5 ; \mathrm{F} 3=11: 5 ; \mathrm{F} 4=8.5: 6 ; \mathrm{F} 5=8.5: 6$; $\mathrm{F} 6=7.5: 7.0 ; \mathrm{F} 7=7.5: 7.0 ;$ clava $=22: 9$.

Mesosoma: Pronotum with distinct median groove, concave posteriormedially. Mesoscutum with MLM longer than broad, $0.75 \mathrm{x}$ length of mesoscutum in dorsal view, convex with raised reticulation and punctae; LLM coarsely reticulate, not smooth, posteriorly with sharp raised dorsal margin; area beyond MLM and between LLM weakly reticulate, with moderately dense, relatively longer silvery hairs, shallowly concave; SAC strongly reticulate as that of MLM; scutellum moderately convex. Prepectus faintly reticulate, subtriangular. Acropleuron longitudinally striate-reticulate. Macropterous; relative lengths of forewing veins: $\mathrm{SMV}=19 ; \mathrm{MV}=13 ; \mathrm{PMV}=6 ; \mathrm{STV}=3$. Midtibial spur as long as midbasitarsus (a little longer than midbasitarsus in the original description of Ferriere, 1935); mid tarsus with a single row of dark pegs on either side ventrally on basal three segments; hindbasitarsus a little longer than following two tarsal segments combined.

Metasoma: a little shorter than mesosoma; T1 longer than $\mathrm{T} 2$, its posterior margin sinuate at middle; $\mathrm{T} 2$ with its posterior margin slightly sinuate at middle; T3 longer than T2; T4 subequal in length to T3; T5 subequal to T4; T6 convex posteriorly; T4 broadest.

Male: Unknown.

\section{Host}

Eggs of Dasynus piperis (Ferrière), Paradasynus rostratus Distant, Amblypelta cocophaga China, Homoeocerus lucidus Linnavuori, (Hemiptera: Coreidae) Axigastus cambell Distant, Diliphus, Nezara viridula L., Vitellus sp. (Hemiptera:
Pentaomidae) (Noyes 2003).

\section{Remarks}

It differs from all other Indian species in havingLLM coarsely reticulate, MS $0.31-0.33 x \mathrm{EH}$ in side view; scrobe separated from front ocellus by 2.5-3.0x diameter of front ocellus; scrobe not connected to front ocellus by a groove or depression, midtibial spur as long as or longer than midbasitarsus, MLM $0.75 \mathrm{x}$ length of mesoscutum and MV shorter than SMV.

\section{Anastatus (A.) donius Narendran sp. nov.}

(Figs. 18-21)

\section{Material examined}

Holotype: Female, India: Kerala, Palghat Dt., Malampuzha, 11.xii.1987, coll. T.C. Narendran \& Party DZUC \# MoEF 1638.

Paratypes: 4 females, India: Kerala, Malappuram Dt., Calicut University Campus, $11^{\circ} 7^{\prime} \mathrm{N} \& 75^{\circ} 5^{\prime} \mathrm{E}, 1 . \mathrm{iii} .1987,17 . \mathrm{ii} .1988$, 1.x.1988, 2.xii.1988, coll. T.C. Narendran \& Party.

Etymology: Arbitrary combination of letters.

Distribution: India (Kerala)

\section{Description}

Holotype Female: Length $2.90 \mathrm{~m}$.

Colour: Dark brown; malar space and vertex with slight metallic green refringence; frons with slight bronze refringence; eyes pale yellowish-gray; ocelli dark brown; antenna brownishblack except scape pale brown; pronotum yellow with spiracular border black, with violet refringence under certain angle of light; mesoscutum dark with metallic green refringence; mid tarsi, apex of $\mathrm{T} 1$ and $\mathrm{T} 2$ completely pale white; rest of metasoma dark brown. Forewing infumated with 2 hyaline

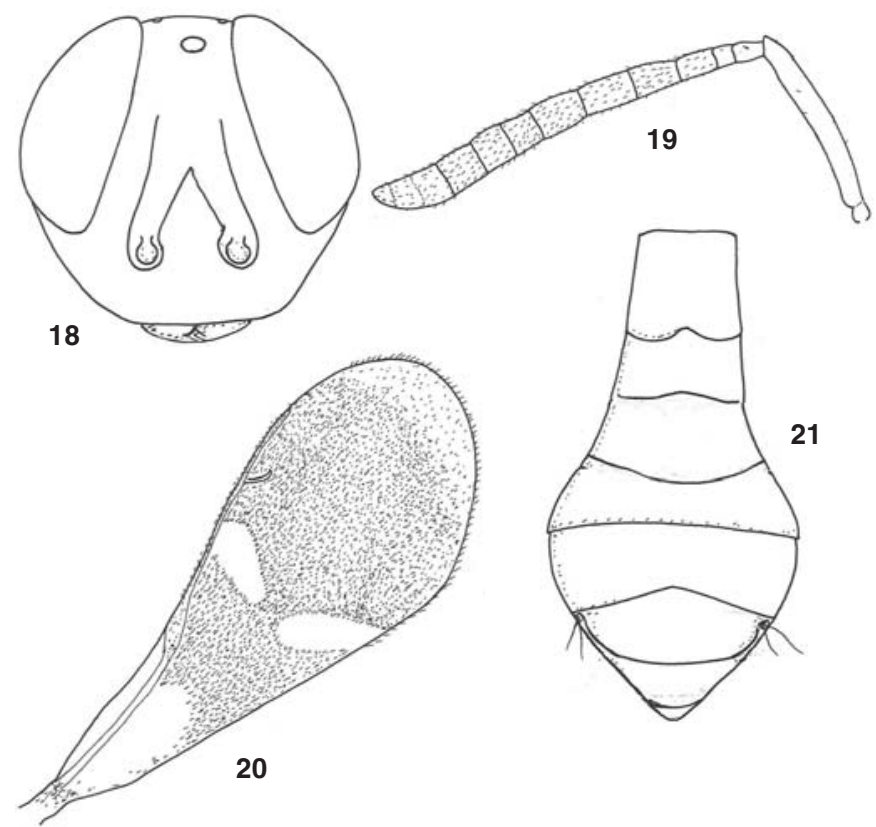

Figures 18-21. Anastatus donius Narendran sp. nov. Female 18 - Head front view; 19 - Antenna; 20 - Forewing;

21 - Metasoma dorsal view 
patches, the anterior hyaline patch not reaching junction of MV and STV (Fig. 3).

Head: A little wider than high in anterior view (65:62), reticulate; lower face with a few white short pubescence; MG almost straight; MS 0.38x EH in side view; EH $1.5 \mathrm{x}$ EW in side view; IAA slightly convex; scrobe not deep posteriorly, lateral margins carinate; scrobe separated from front ocellus by a distance more than diameter of front ocellus; OOL: POL: LOL $=1: 5: 3$; scrobal margin weakly incurved above torulus, scrobe reticulate, IAA and lower face coriaceous. Relative measurements of $\mathrm{L}: \mathrm{W}$ of antennal segments: scape $=43: 5$; pedicel $=7: 4 ;$ anellus $=4: 5 ; \mathrm{F} 1=9: 5 ; \mathrm{F} 2=10: 6 ; \mathrm{F} 3=12: 7 ; \mathrm{F} 4$ $=11: 8 ; \mathrm{F} 5=7: 8 ; \mathrm{F} 6=8: 8 ; \mathrm{F} 7=9: 9 ;$ clava $=15: 9$.

Mesosoma: Pronotum bear dorsally, weakly reticulate, medially divided by a weak longitudinal median line, posteromedially with a shallow depression. Mesonotum with MLM densely reticulate-punctate, $0.65 \mathrm{x}$ dorsal length of mesoscutum; LLM similarly sculptured as MLM, with sharp raised dorsal margin on posterior half; interspace between lateral lobes behind MLM shallowly concave, faintly reticulate medially, sides reticulate; mesoscutum with scattered dirty white setae medially and in row on lateral lobes, scutellar axillar complex reticulate punctate; axillae broadly separate anteromedially; scutellum distinctly convex, apex rounded. Metanotum smoothly sculptured with dorsellum slightly extended over scutellar apex. Propodeum without median carina. Prepectus subtriangular, smoothly and weakly reticulate. Acropleuron very finely and faintly coriaceous. Macropterous, forewing extended to apex of gaster, with apical margin rounded (Fig. 20); SMV a little longer than MV; relative length of veins: $\mathrm{SMV}=39 ; \mathrm{MV}=36 ; \mathrm{PMV}=17 ; \mathrm{STV}=6$. Midtibial spur slightly longer than mid basitarsus; midtarsus with single row of dark pegs ventrally on either side on basal four segments; hind basitarsus subequal to following three segments combined.

Metasoma: Longer than mesosoma (32: 26); T1 longer than T2, its posterior margin incised medially; T2 shorter than T3, its posterior margin slightly concave; T3 longer than T4; T5 large with its posterior margin broadly concave; $\mathrm{T} 6$ with convex posterior margin; $\mathrm{T} 7$ as in figure 4; $\mathrm{T} 4$ and $\mathrm{T} 5$ broader than all other tergites. Ovipositor sheath not exserted.

Variation: Length varies from 2.4-3.0mm Mesopleuron becomes a little more darkish-brown in one paratype. MS varies from 0.24 to $0.38 \mathrm{x} \mathrm{EH}$ in side view. $\mathrm{EH} 1.5-1.8 \mathrm{x} \mathrm{EW}$.

\section{Host: Unknown.}

\section{Remarks}

This new species is similar to $A$. mantoidae Motsch. Because it has T5 deeply incised but differs from $A$. mantoidae in having a forewing with two hyaline patches as in Fig. 20.

\section{Anastatus (A.) echidna Motschulsky}

Cacotropia echidna Motschulsky, 1863: 55-57, Lectotype Female. Sri Lanka (= Ceylon) (ZMMS). Designated by Bouček 1988. Anastatus echidna (Motschulsky); Bouèek, 1988: 550.

Matarial examined: None.

Distribution: Sri Lanka (= Ceylon)
Diagnosis (based on original description and Bouček 1988)

This species belongs to the bifasciatus group of Anastatus (Bouček 1988). Female length $3.25 \mathrm{~mm}$. General body colour black, metallic, more or less shiny; frons coppery, anterior part of metasoma whitish, posterior part of metasoma subviolaceous, tip greenish; scape, lateral parts of mesosoma, basal portion of tibiae and tip of tarsi more or less rufotestaceous; pronotum metallic green; forewing infuscated with two oblong translucent (whitish of Bouèek, 1988) spots near the tip; ocelli piceous; eye reddish.

Head roundly triangular, rugulose, scrobe with two channels like depressions; antenna hardly clavate. Mesosoma oblong, moderately, very densely and obscurely punctate, on the sides glabrous, shining. Pronotum moderately longitudinally hollowed out, on sides convex, raised; mesonotum flat, ovate, velvetty black; propodeum unequally trapezoidal, shining. .

Male: Unknown.

Host: Unknown.

\section{Remarks}

My efforts to procure the type did not materialize. In the absence of enough reliable information on the species, I have based the above account mainly on a translation of the original description of Motshulsky (1863) and on information provided by Boucek (1988).

\section{Anastatus (A.) hayati Narendran sp. nov.}

(Figs. 22-25)

\section{Material examined}

Holotype: Female, India: Kerala, Malppuram Dt., Calicut University Campus, $11^{\circ} 7^{\prime} \mathrm{N} \& 75^{\circ} 5^{\prime} \mathrm{E}$, 09.ii.1988, coll. T.C. Narendran \& Party DZUC \# MoEF 1642.

Paratypes (9 females): 9 females, India: same collection data of holotype except date 19.iii.1985 (2); Kerala, Malappuram Dt., Calicut University Campus, $11^{\circ} 7^{\prime} \mathrm{N} \& 75^{\circ} 5^{\prime} \mathrm{E}$, 5.ii.1989, coll. T.C. Narendran \& Party (2); Kerala, Malppuram Dt., Calicut University Campus, $11^{\circ} 7^{\prime} \mathrm{N} 75^{\circ} 5^{\prime} \mathrm{E}$, 19.i.1989, coll. T.C. Narendran \& Party (1); Kerala, Malappuram Dt., Calicut University Campus, $\left.11^{\circ} 7^{\prime} \mathrm{N} \& 75^{\circ} 5^{\prime} \mathrm{E}\right)$, 1.x.1988, coll. K. Anil (1); Karnataka, Vittal, CPCRI $12^{\circ} 46^{\prime} \mathrm{ON} \& 75^{\circ} 4{ }^{\prime} 60 \mathrm{E}$, 16.xii.1988, coll. T.C. Narendran \& Party (1); Kerala, Malappuram Dt., Calicut University Campus, $11^{\circ} 7^{\prime} \mathrm{N} \& 75^{\circ} 5^{\prime} \mathrm{E}$, 17.i.1990, coll. K. Anil (1); Karnataka, Lakavalli Forest, $13^{\circ} 42^{\prime} \mathrm{N} \& 75^{\circ} 40^{\prime} \mathrm{E}, 5 . x i .2006$, coll. K. Rajmohana (ZSI) (1).

\section{Etymology}

Named after Prof. M. Hayat of Aligarh Muslim University, Aligarh, India, for his sincere cooperation in my studies on Eupelmidae and for his significant contribution in the study of Eupelmidae.

\section{Description}

Holotype Female: Length $3.1 \mathrm{~mm}$.

Colour: Head metallic green; eyes pale yellow; ocelli pale reflecting yellow; scape pale brownish-yellow, remaining segments of antenna dark brown; pronotum pale brownish yellow, with rim of spiracles black; MLM dark brown, LLM pale brownish-yellow; area between lateral lobes beyond MLM 


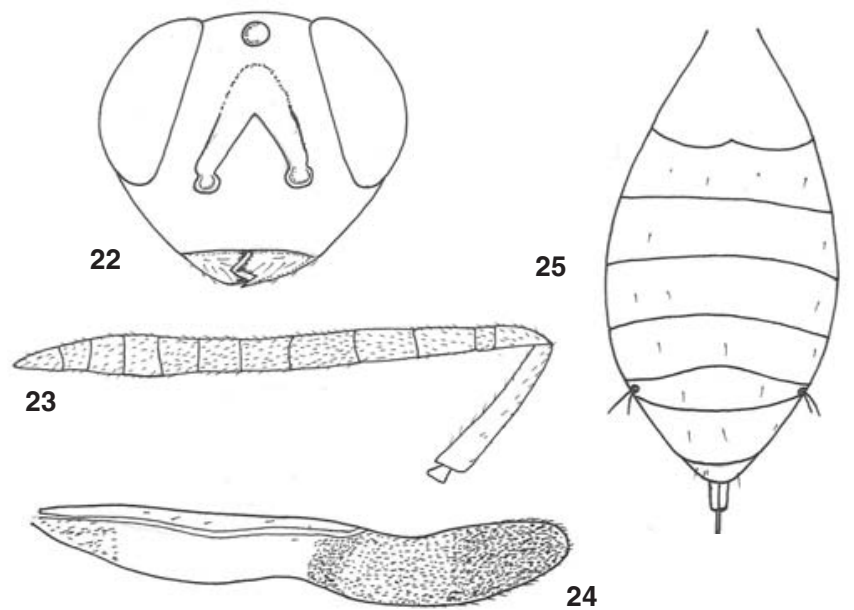

Figures 22-25. Anastatus hayati Narendran sp. nov. Female 22 - Head front view; 23 - Antenna; 24 - Forewing;

25 - Metasoma dorsal view

dark with metallic bluish-green refringence; scutellar axillar complex, metanotum and propodeum dark brown; acropleuron pale yellowish-brown; prepectus pale yellow; T1 brown with apical half pale; T2 pale except distal margin, remaining tergites dark brown with metallic green refringence on $\mathrm{T} 7$; ovipositor sheath pale yellow; legs brown with tibiae slightly darker and tarsus paler and mid tibial spur pale yellow. Forewing (Fig. 24) with approximate distal half infumate with a less pigmented part in the middle, the infumate area is followed by hyaline part behind SMV and another infumate smaller part at base of wing.

Head: A little wider than high in anterior view (68: 61), strongly reticulate; face below toruli and IAA with moderately dense pale brownish white pubescence; MS 0.36x EH in side view; MG almost straight, slightly curved posteriorly just before meeting lower margin of MS; IAA convex and strongly reticulate; scrobe relatively deep, lateral margin carinate; scrobe separated from front ocellus by diameter of front ocellus, scrobe reticulate; OOL: POL: $L O L=2.5: 5: 3$. Relative measurements of L: W of antennal segments: scape $=39: 7$; pedicel $=13: 5$; anellus $=5: 6 ; \mathrm{F} 1=14: 7 ; \mathrm{F} 2=15: 7.5 ; \mathrm{F} 3=$ 16: $8 ; \mathrm{F} 4=12: 8 ; \mathrm{F} 5=10: 8 ; \mathrm{F} 6=9: 9 ; \mathrm{F} 7=8: 10 ;$ clava $=26$ : 10 .

Mesosoma: Pronotum with weak median groove, slightly depressed posteromedially. Mesonotum with MLM 0.71x length of mesoscutum in dorsal view, slightly convex, distinctly reticulate; LLM weakly reticulate, mostly smooth, with dorsal margin raised in posterior half; interspace between lateral lobes beyond MLM mostly smooth and shiny; mesoscutum moderately pubescent; scutellar axillar complex reticulate; scutellum weakly convex. Prepectus subtriangular, weakly sculptured, mostly smooth and shiny. Acropleuron longitudinally striate. Brachypterous, forewing reaching hind margin (or a trifle exceeding) of T1. Mid tibial spur subequal to mid basitarsus; mid tarsus with single row of dark peg ventrally on either side on basal four segments; hind basitarsus subequal to following two segments combined.

Metasoma: A little longer than mesosoma (15:13), a little more than $2 \mathrm{x}$ its width, T1 with posterior margin incised at middle, T2 as long as T3; T4 broadest, as long as T3; T5 almost equal in length to $\mathrm{T} 4$; remaining tergites narrowing towards caudal end. Ovipositor sheath exserted slightly.

Variation: Length 2.1-3.0mm. Metallic green refringence faded in some specimens.

Host: Unknown

\section{Remarks}

This comes near A.rufopostumus in having similar colour of head and acropleuron. However, A. hayati differs in having T7 dark brown or black, scape shorter than combined length of $\mathrm{F} 1$ to F3, MLM dark metallic green, and clava pointed (Fig. 23).

\section{Anastatus (A.) japonicus Ashmead}

(Figs. 26-27)

Anastatus japonicus Ashmead, 1904: 153, Female,Japan (USNM). Anastatus bifasciatus disparis Ruschka, 1921: 265. Synonymy by Tachikawa 1965: 281.

Anastatus uaponicus Ashmead; He et al. 2001: 21-23. Misspelling of A. japonicus Ashmead (Noyes 2003).

\section{Material examined}

1 female, India, Uttar Pradesh, Aligarh $27^{\circ} 54^{\prime} \mathrm{N} \& 78^{\circ} 4^{\prime} \mathrm{E}$, 1.x.1979, coll. M. Hayat.

\section{Distribution}

Widely distributed in Palaerctic, Nearctic and Oriental regions (Noyes 2003). In India Himachal Pradesh (Dharmadhikari et al. 1985), Jammu and Kashmir (Islam \& Hayat 1986). Uttar Pradesh, Aligarh (New record)

\section{Redescription}

Female: Length: 2-3.1 mm.

Colour: Black with metallic, bronzy refringence as follows: frontovertex, MLM, scutellum with bronzy-blue, gena with deep blue, sides and posterior part of mesoscutum with deep bluish-violet and gaster with dull purple blue; antennae (Fig. 52 ) dark brown with scape yellowish-brown; pronotum yellowish brown with rim of spiracles dark brown or black; prepectus and tegulae brown; acropleuron brown with anterior third black. Forewing infumated with a transverse hyaline band bhind MV, outer margin of hyaline band curved, not extending upto junction of MV and STV (Fig. 27), apex not distinctly differentialted by weak pigmented area.

Head: wider than high in anterior view, distinctly reticulate;

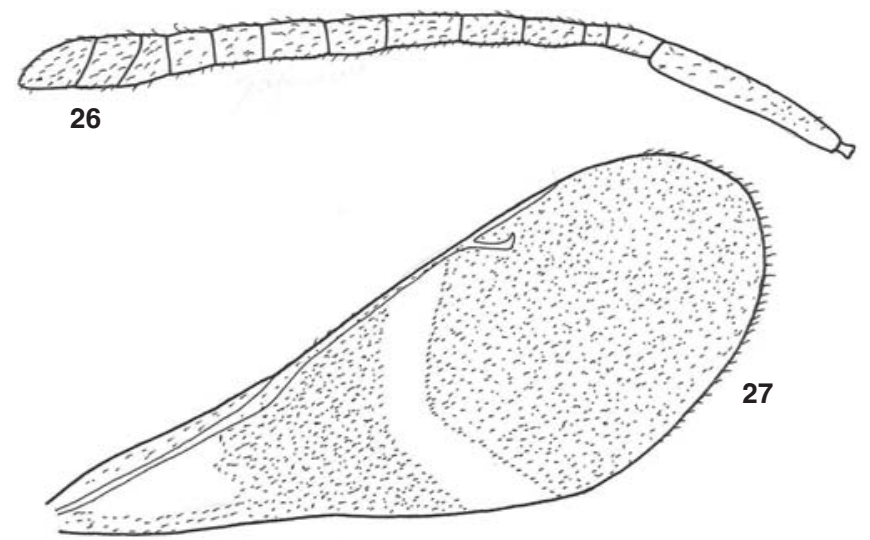

Figures 26-27. Anastatus japonicus Ashmead: Female 26 - Antenna; 27 - Forewing 
IAA and ventral half of frons with moderately dense pilosity. MS 0.40-0.41x EH in side view; MG slightly curved towards posterior side; IAA very convex, well reticulate; scrobe not deep, channel like, posteriorly shallow, lateral margin carinate, separated from front ocellus by diameter of front ocellus; scrobe connected to front ocellus by a very narrow shallow groove; OOL: POL: LOL = 1:4-4.5: 3. Relative measurements of L;W of antennal segments : scape $=24: 4$; pedicel $=6: 3$; anellus $=$ $3: 2 ; \mathrm{F} 1=7: 3 ; \mathrm{F} 2=7.5: 3 ; \mathrm{F} 3=9: 4 ; \mathrm{F} 5=8: 4 ; \mathrm{F} 6=6: 5 ; \mathrm{F} 7=$ $5: 5 ;$ clava $=18: 6$.

Mesosoma: Pronotum with distinct median groove, concave posteriomedially. Mesocutum with MLM distinctly longer than broad, 0.63-0.68x length of mesoscutum in dorsal view; MLM convex, distinctly reticulate-punctate; LLM distinctly reticulate, dorsal margin raised, sharp posteriorly; area beyond MLM and between LLM somewhat deeply concave, mostly smooth and shiny with sparse pubescence. SAC strongly reticulate-punctate; scutellum slightly convex. Prepectus subtriangular, smooth. Acropleuron finely reticulate. Macropterous; relative lengths of forewing veins: $\mathrm{SMV}=29$; $\mathrm{MV}=28 ; \mathrm{PMV}=11 ; \mathrm{STV}=4$. Midtibial spur almost equal in length to corresponding basitarsus; midtarsus with a single row of dark pegs on either side ventrally of basal four segments; hind basitarsus as long as following two segments combined.

Metasoma: slightly longer than mesosoma (53:50). T1 longest, its posterior margin incised at middle; $\mathrm{T} 2$ shorter than T3; T4 slightly longer than T3; T5 almost equal to T4; T6 with posterior margin convex; $\mathrm{T} 7$ broadly expanded; T5 broadest.

Variation: provided in the text above.

Male: For description see Ashmead (1904).

\section{Host}

Eggs of Lymantria dispar (L.) (Lepidoptera: Lymantriidae) and those of several other Lepidoptera and Hemiptera families, sometimes as a hyperparasitoid through Braconidae and Encyrtidae (Noyes 2003).

\section{Remarks}

This species in the earlier literature was often misidentified as Anastatus bifasciatus (Geoffroy) or Anastatus disparis Ruschka (Gibson 1995; Noyes 2003).

\section{Anastatus (A.) kashmirensis Mathur}

Anastatus kashmirensis Mathur, 1956: 93, Female (holotype), male, India, Srinagar (FRI).

\section{Matarial examined: None.}

Distribution: India: Jammu \& Kashmir (Sri Nagar).

Diagnosis (based on Mathur (1956), Mani (1988), and Hayat (1975))

Female: $1.50-2.00 \mathrm{~mm}$.

Colour: Head metallic green with a coppery refringence; frons and face with purple refringence; scape brownish-yellow; pedicel green, rest dark brown; pronotum metallic blue with a median orange stripe, brownish-yellow laterally; mesonotum metallic bluish-green with a purplish refringence; scutellum with a coppery tinge; propodeum purplish; acropleuron fuscous with purplish tinge anteriorly and testaceous posteriorly; coxa, trochanter and three middle tarsal segments brownish-yellow; coxa partly greenish outwardly; femur, tibia and apical tarsal segments dark brown; metasoma aeneous with a broad dull white band on basal two tergites; T1 with 2 dark brown lateral spots; tip of metasoma dark green; ovipositor pale; forewing infumated with transverse hyaline band below MV, area below SMV also hyaline; outer margin of hyaline band curved, hyaline band commencing from the junction of MV and STV, and width of hyaline band below MV a little shorter than SMV.

Head: wider than long, vertex and frons finely granulate; scrobe moderately deep, strongly carinate on lateral margin and anterior margin, separated slightly(less than diameter of front ocellus) away from front ocellus; face elevated and rugulose. Relative L:W of antennal segments : scape $=17: 2.5$; pedicel $=5: 3 ;$ anellus $=1: 2 ; \mathrm{F} 1=5: 3 ; \mathrm{F} 2=3.5: 3 ; \mathrm{F} 3=3.6: 4$; $\mathrm{F} 4=3: 4 ; \mathrm{F} 5=3: 4 ; \mathrm{F} 6=3: 4 ; \mathrm{F} 7=3: 4 ;$ clava $=12: 4(\mathrm{Fig} .159 \mathrm{c}$, Mani 1989).

Mesosoma: Pronotum slightly broader than long; "scutum"(MLM?) punctate, closely reticulate with impressed lines(notauli?); "scapulae" (LLM) weakly reticulate anteriorly; SAC finely and longitudinally striate; acropleuron finely lineolate, sparsely hairy anteriorly. Forewing veins with MV shorter than SMV; STV about one-third as long as MV; midtibial spur distinctly longer than midbasitarsus; midtarsus with a row of black pegs on either side ventrally of basal 4 segments.

Metasoma: slightly longer than mesosoma, narrow at base, widest at T5, strongly narrowed apically. Ovipositor slightly exserted.

\section{Host}

Lymantria obfuscata Walker, Lymantria dispar (L.) (Lepidoptera: Lymantriidae) (Hayat 1975).

\section{Remarks}

A. kasmirensis comes near $A$. leithi in having forewing hyaline band not extending to junction of MV and STV and in some other features but differs from leithi in having mesonotum metallic bluish-green with purplish refringence except scutellum with coppery tinge, scutellar axillar complex longitudinally striate and MV a little less than 2x as long as SMV.

\section{Anastatus (A.) latheefi Narendran sp. nov.}

(Figs. 28-31)

\section{Material examined}

Holotype: Female, India: Andra Pradesh, Kottanada,

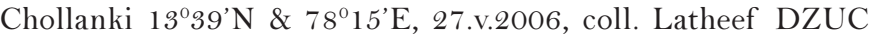
\# MoEF 1640.

\section{Etymology}

The species is named after the collector.

\section{Description}

Holotype: Female: Length $4.6 \mathrm{~mm}$

Colour: Black with following parts as follows: antennal scape pale brownish-yellow; metallic green refringence on frontovertex, gena and temple, posterior corners of pronotum, sides and median concave part of mesoscutum and on scutellar axillar complex; frons with bronze refringence; pronotum pale brownish-yellow with posterior corners dark with metallic 


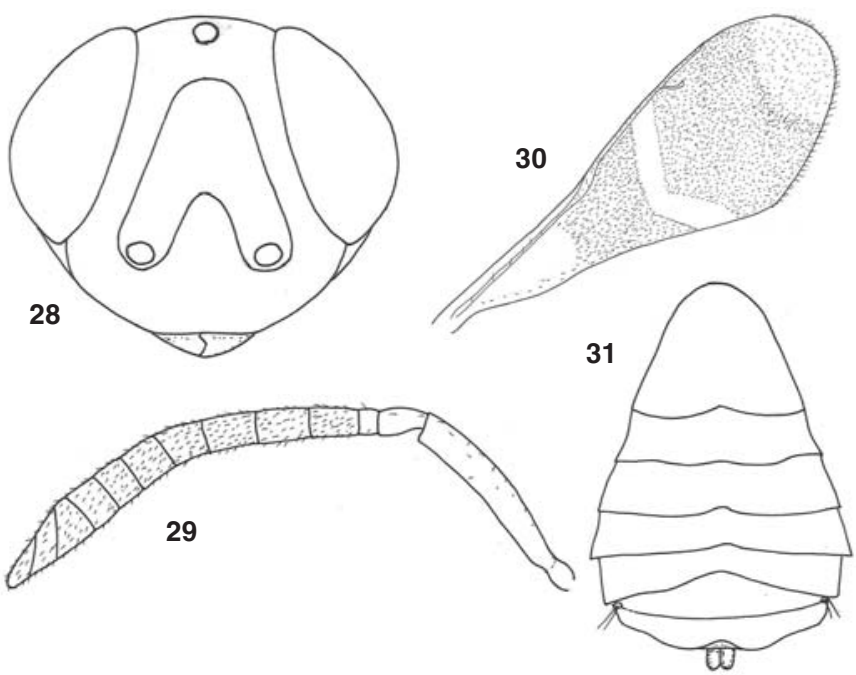

Figures 28-31. Anastatus latheefi Narendran sp. nov. Female 28 - Head front view; 29 - Antenna; 30 - Forewing;

31 - Metasoma dorsal view

refringence; prepectus pale brownish-yellow; median and apical part of T1 and T2 pale whitish-yellow; ovipositor sheath pale yellow; front legs brown, midlegs brown with femur and tarsus darker; hind leg dark brown with bases of femur and tibia, second to fifth tarsal segments dark brown. Forewing infumate with hyaline band not reaching junction of MV and STV, outer margin of band angulate (Fig. 30).

Head: Wider than long high in anterior view (72: 64), coarsely reticulate; lower face with moderately dense white pubescence; MS 0.33x EH in side view; MG well curved; IAA convex, reticulate; scrobe somewhat deep, lateral margins carinate; scrobe separated from front ocellus by $1.5 \mathrm{x}$ diameter of front ocellus; scrobe reticulate; OOL: POL: LOL $=2: 7: 4$ Relative measurements of $\mathrm{L}: \mathrm{W}$ of antennal segments: scape $=41: 7$; pedicel $=10: 6$; anellus $=5: 4 ; \mathrm{F} 1=10: 6 ; \mathrm{F} 2=11: 7 ; \mathrm{F} 3$ $=11: 7 ; \mathrm{F} 4=9: 8 ; \mathrm{F} 5=8: 8 ; \mathrm{F} 6=9: 6 ; \mathrm{F} 7=10: 6 ;$ clava $=23: 12$.

Mesosoma: Pronotum weakly reticulate, medially depressed, divided medially by a weak longitudinal line. Mesonotum with MLM distinctly reticulate-punctate, $0.6 \mathrm{x}$ dorsal length of mesoscutum; LLM striate-reticulate, with raised median edge in posterior half; interspace between lateral lobes behind MLM deeply concave, weakly reticulate, mostly smooth and shiny; mesoscutum with moderately dense white pubescence medially and in rows on lateral lobes; scutellar axillar complex densely micropunctate; scutellum distinctly convex, apex rounded. Propodeum without median carina, separated from callar region by plical furrow. Prepectus subtriangular, weakly reticulate. Acropleuron longitudinally striate. Macropterous; forewing with relative length of veins $=\mathrm{SMV}=55 ; \mathrm{MV}=34 ; \mathrm{PMV}=17 ; \mathrm{STV}=6$. Midtibial spur subequal to midbasitarsus; midtarsus with a single row of dark pegs ventrally on either side on basal three segments; hind basitarsus as long as following three segments combined.

Metasoma: (Fig. 31) Subequal in length to mesosoma; T1 longer than T2; T3 almost as long as T2; T4 shorter than T3; T5 slightly shorter medially than T4; width gradually increasing from $\mathrm{T} 1$ to $\mathrm{T} 4$ and $\mathrm{T} 5$.

Host: Unknown.

\section{Remarks}

This new species resembles $A$. tenuipes Boliver in somewhat similar coloured mesosoma but differs from it in not having all funicular segments longer than wide and in having different colouration of the antennae and head.

\section{Anastatus (A.) leithi (Walker)}

(Fig. 32)

Eupelmus leithi Walker, 1872: 83, Lectotype female, India (Nr. Bombay) (BMNH) (examined), designated by Bouček, 1979: 96.

Anastatus leithi (Walker); Bouček, 1979: 96.

\section{Material examined}

Lectotype (Female), India: Bombay, B.M. Type \# Hym. 5. 974

\section{Distribution}

India and Sri Lanka

\section{Diagnosis}

Lectotype: Female: Length $3.18 \mathrm{~mm}$.

Colour: Body dark brown; head metallic green with bronzy tints; antenna black with scape pale brown; foreleg, hind tarsus and ovipositor sheath pale brown; ocelli red; metasoma at base pale white. Forewing infumated as in figure 66, with hyaline band below MV extending to junction of MV and STV; apex of forewing with infumation thinner (weaker pigmentation); base of forewing behind SMV hyaline.

Head: $1.43 \mathrm{x}$ wider than high in frontal view with reticulate sculpture; lower face with white short hairs; MG distinct and straight; MS 0.4x EH, smoothly rounded to occiput; eye red; inter antennal area convex; scrobe not deep, lateral margins carinate, ending about one ocellar diameter before front ocellus; ocellar region slightly raised, ocelli in a broad triangle; OOL = 5 ; POL $=25$; vertex with posterior margin incurved and carinate. Antenna with scape slightly expanded towards apex, curved, anellus as long as wide (rest of antenna missing).

Mesosoma: Pronotum medially divided by a line of weak sclerotization. Mesonotum with mesoscutum slightly broader than long; MLM 0.48x length of mesoscutum, slightly reticulate punctate but rest of mesoscutum finely sculptured; LLM with a shallow cross furrow in posterior half; SAC almost in same plane and with sculpture similar to MLM; axillae widely separated anteromedially. Metanotum with dorsellum broad, convex. Propodeum with plical region narrow, transverse, without median carina, posterior margin deeply concave. Acropleuron longitudinally striate. Macropterous; MV almost equal to SMV (38:40); PMV 2.4x STV.

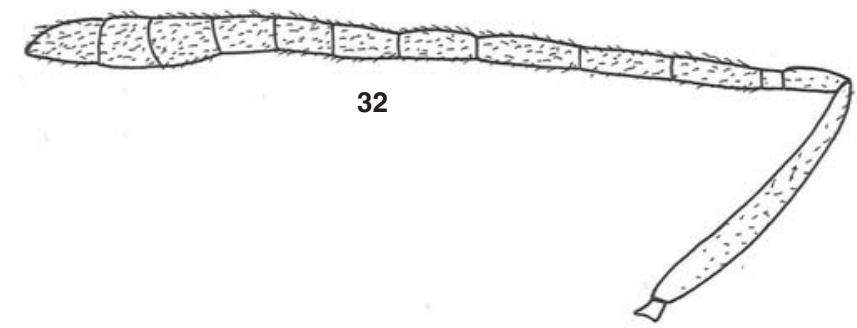

Figure 32. Anastatus leithi (Walker). Female 32 - Forewing 
Metasoma: Shorter than mesosoma; finely sculptured; T1 longer than T2; posterior margin of T2 deeply incised medially; posterior margin of T3 to T5 somewhat straight; posterior margin of T 6 convex; apex of last tergite with a stiffened slightly upturned rim; ovipositor sheath protruding, $0.16 \mathrm{x}$ of metasoma and $0.23 \mathrm{x}$ length of hind tibia.

Male: Unknown.

Host $1872)$.

Blister galls on leaves of Duranta sp. (Verbenaceae) (Walker,

\section{Remarks}

The lectotype female is not in a good condition. Scape, pedicel and anellus intact, rest of antenna, mid legs and hind tarsi missing. Bouček (1979) stated that $A$. leithi is very similar to $A$. ramakrishnai. However, $A$. leithi differs from $A$. ramakrishnai in having 1: fore femur without denticle; 2) hyaline band is almost equal in width throughout; 3 ) MV almost $2 \mathrm{x}$ as wide as length of STV (measured to the apex of uncus); 4) apex of forewing weakly pigmented and looks lighter than remaining infuscation and 5) ovipositor sheath not concealed.

\section{Anastatus (A.) libratus Narendran sp. nov.}

(Figs. 33-38)

\section{Material examined}

Holotype: Female, India: Kerala, Malappuram Dt., Calicut University Campus, $11^{\circ} 7^{\prime} \mathrm{N} \& 75^{\circ} 5^{\prime} \mathrm{E}, 12$. iii.1985 DZUC \# MoEF 1644), coll. T.C. Narendran.

Paratypes: 3 females, India: Kerala, Malappuram Dt., Calicut University Campus, $11^{\circ} 7^{\prime} \mathrm{N} \& 75^{\circ} 5^{\prime} \mathrm{E}, 14 . \mathrm{v} .1989$, 8.v.1988, coll.

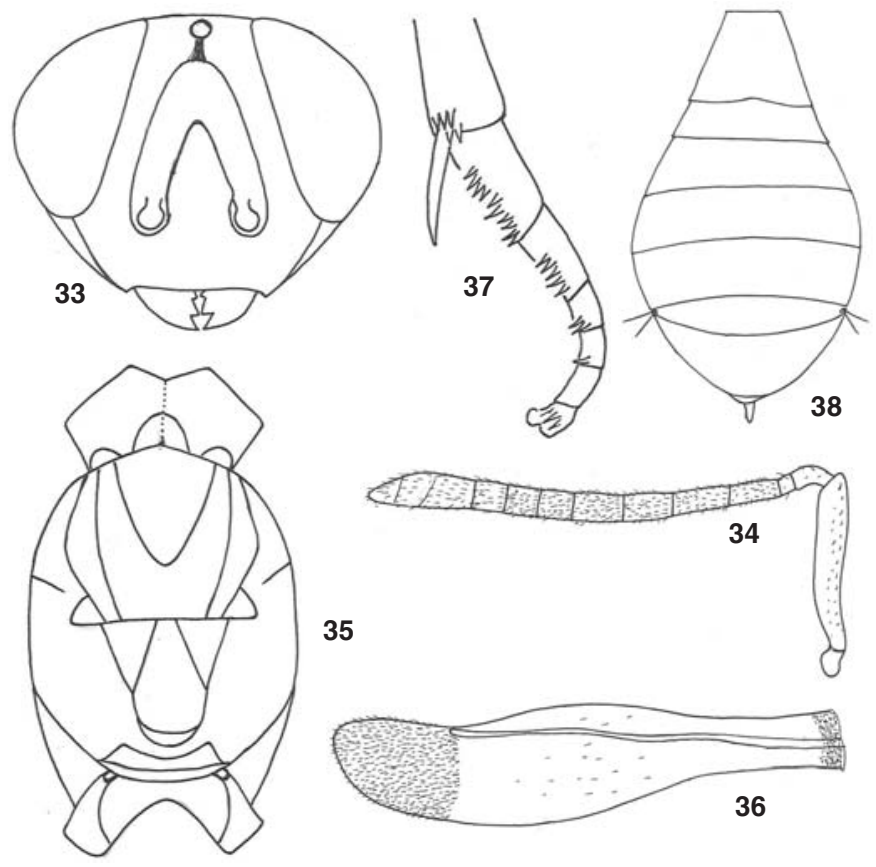

Figures 33-38. Anastatus libratus Narendran sp. nov. Female

33 - Head front view; 34 - Antenna; 35 - Mesosoma dorsal view; 36 - Forewing; 37 - Apex of mid tibia and mid tarsi;

38 - Metasoma dorsal view
T.C. Narendran (2); 1 Female, Kerala, Malappuram Dt., Nilambur, $11^{\circ} 16^{\prime} \mathrm{N} \& 76^{\circ} 14^{\prime} \mathrm{E}$, 22.iv.1988, coll. T.C. Narendran (1).

\section{Etymology}

The species name is an arbitrary combination of letters.

\section{Description}

Holotype: Female: Length $2.7 \mathrm{~mm}$

Colour: Head metallic green with bronzy tint on frons; IAA with purple tints; scape pale brownish yellow, but rest of antenna black; eyes dark brown; ocelli pale reflecting yellow; mesosoma yellowish-brown with pronotal spiracles black on rim; legs mostly yellowish brown with midtarsi and midtibial spur pale brownish-yellow. Forewing infumate on distal 0.24 part and at base' remaining part inbetween hyaline.

Head: A little wider than high in anterior view (69: 60), distinctly reticulate; ventral half of frons with moderately dense pilosity; MS 0.55x EH in profile; MG slightly curved towards posterior side; IAA coarsely reticulate; scrobe deep, margins carinate, separated from front ocellus by $1.25 \mathrm{x}$ diameter of front ocellus; scrobal impression reticulate; scrobe connected to front ocellus by fovea; OOL: POL: $\mathrm{LOL}=2: 5: 2$. Relative measurements of $\mathrm{L}: \mathrm{W}$ of antennal segments: scape $=43: 7$; pedicel $=10: 5$; anellus $=4: 4 ; \mathrm{F} 1=12: 5 ; \mathrm{F} 2=14: 5 ; \mathrm{F} 3=12$ : $6 ; \mathrm{F} 4=12: 7 ; \mathrm{F} 5=8: 7 ; \mathrm{F} 6=8: 7 ; \mathrm{F} 7=8: 7 ;$ clava $=25: 9$.

Mesosoma: Pronotum with a weak median groove, concave posteromedially. Mesonotum with MLM distinctly longer than broad, $0.66 \mathrm{x}$ length of mesoscutum in dorsal view, almost flat, weakly reticulate; LLM smooth with sharp raised dorsal margin; MLM sparsely pubescent, area between lateral lobes behind MLM smooth and shiny with sparse pubescence; scutellar axillar complex moderately reticulate; scutellum almost flat. Prepectus subrectangular, hardly reticulate. Acropleuron weakly and longitudinally striate-reticulate. Brachypterous; not extending beyond posterior margin of $\mathrm{T} 1$. Midtibial spur almost equal in length to mid basitarsus; midtarsus with single row of dark pegs ventrally on either side on basal four tarsal segments; hind basitarsus subequal to combined length of following three segments.

Metasoma: Subequal in length to mesosoma in dorsal view; 1.9x as long as wide; T1 2x as long as T2; T3 as long as T2; T4 broadest and longer than T3; T5 to caudal end gradually narrowed (Fig. 38). Ovipositor sheath slightly exserted posteriorly.

Variation: Length $2.7-3.5 \mathrm{~mm}$. In larger specimens acropleuron a little more brownish.

\section{Host: Unknown.}

\section{Remarks}

This new species differs from all other brachypterous Indian species in having MLM almost flat and SAC orange yellow.

\section{Anastatus (A.) mantoidae Motschulsky}

(Fig. 39)

Anastatus mantoidae Motschulsky, 1859: 116. Lectotype female, Sri Lanka (ZMMS), designated by Bouček, 1988: 550. Anastatus mantoidae Motschulsky; Mani, 1938: 42.

Material examined: None. 


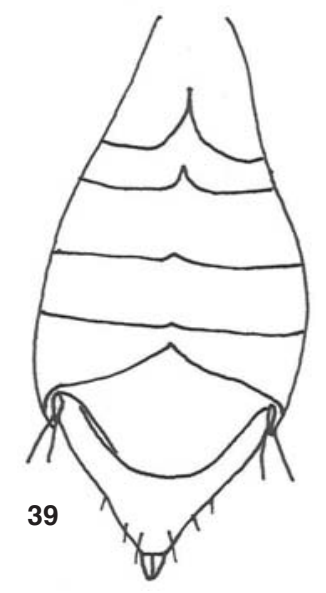

Figure 39. Anastatus mantoidae Motschulsky Female 39 - Metasoma dorsal view

Distribution: Sri Lanka (= Ceylon)

Diagnosis (based on Bouček 1988 and Gibson 1995):

Female: Length $3.75 \mathrm{~mm}$. Apical metasomal tergite is rounded but rather narrow (Fig. 988, Bouckek 1988), its rim hardly upturned and the margin of T5 is rather deeply excised; Forewing with only a circular infumate region behind STV and PMV and with a paler spot anteriorly in the infumation but all setae brownish.

Male: Unknown.

Host: Ootheca of praying mantis, Mantis sp. (Orthoptera: Mantidae).

\section{Remarks}

Figure 160 of Mani (1989) looks like a Podagrion (Torymidae). Hence it is difficult whether the account given by Mani (1989) is applicable to the lectotype female selected by Boucek (1988). Gibson (1995) states that females of $A$. mantoidae lack the typical forewing colour pattern of Anastatus. According to him all setae of forewing are brownish and there is only a more or less circular infuscate region behind the stigma and PMV.

\section{Anastatus (A.) mohanae Narendran sp. nov.}

\section{Material examined}

(Figs. 40-43)

Holotype: Female, India: Karnataka, Sukhalhetti Guest House, Lakavalli, $13^{\circ} 42^{\prime} \mathrm{N} \& 75^{\circ} 40^{\prime} \mathrm{E}$, 4.xii.2006 coll. K. Rajmohana DZUC \# MoEF 1645.

Paratypes: 3 females, India: Kerala, Malappuram Dt., Calicut University Campus, $11^{\circ} 7^{\prime} \mathrm{N} \& 75^{\circ} 5^{\prime} \mathrm{E}, 12 . \mathrm{i} .1989,25 . \mathrm{i} .1989$, 27.i.1989, coll. T.C. Narendran \& Party.

\section{Etymology}

Species name is a combination of letters taken from part of the name of Dr. (Mrs). Rajmohana who collected the holotype.

\section{Description}

Holotype: Female: Length $3.1 \mathrm{~mm}$.

Colour: Head metallic green; eyes pale yellow with brownish patches; ocelli pale reflecting yellow; antenna black

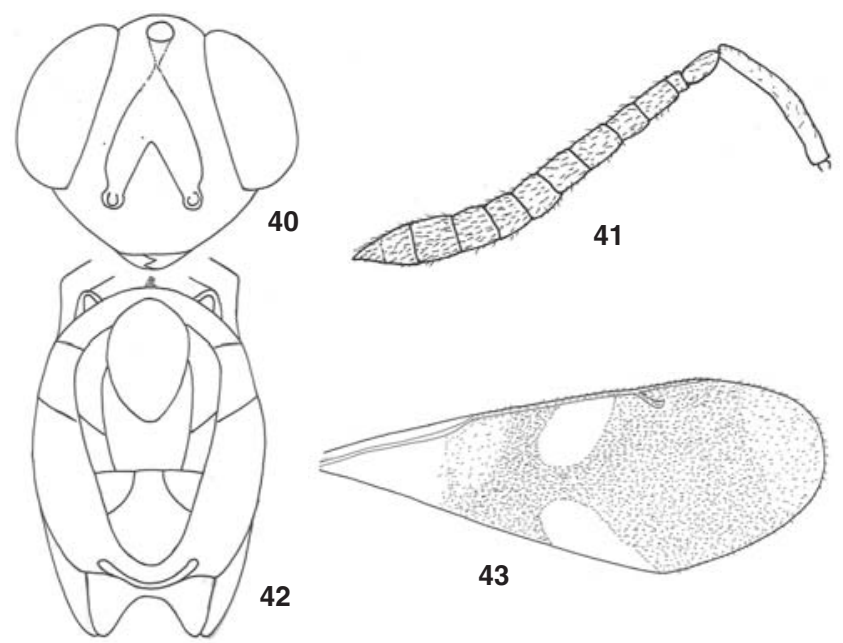

Figures 40-43. Anastatus mohanae Narendran sp. nov. Female 40 - Head anterior view; 41 - Antenna; 42 - Mesosoma dorsal view; 43 - Forewing

with scape pale yellow; pronotum pale brownish-yellow with spiracular rim black; mesonotum pale yellowish-brown with mesoscutum ecept LLM dark brown with metallic green refringence; LLM pape brownish yellow; SAC black with metallic green refringence; propodeum dark brown with middle part pale brownish-yellow; late, prepectus pale brownishyellow; acropleuron pale brownish-yellow with apical part darker; legs mostly pale brownish-yellow with median parts of femora slightly darker; gaster at base pale yellow. Forewing with two hyaline spots one behind the other behind MV, basal part of forwing hyaline; apex of forewing weakly pigmented (Fig.43).

Head: A little wider than high in anterior view (69: 63), distinctly reticulate; IAA and ventral half of frons with moderately dense white pilosity; MS 0.36x EH; MG slightly curved posteriorly; IAA slightly convex, well reticulate, with moderate dense pubescence between toruli; area below IAA with moderately dense pubescence; scrobe shallow, lateral margins carinate, separated from front ocellus by diameter of front ocellus; scrobal impression reticulate; scrobe connected to front ocellus by a shallow broad depression; OOL: POL: LOL = 1; 4: 2. Relative measurements of L: $\mathrm{W}$ of antennal segments: scape $=31: 4$; pedicel $=8: 4$; anellus $=4: 4 ; \mathrm{F} 1=8: 5 ; \mathrm{F} 2=7$ : 5; F3 = 8: 6; F4 =8: 7; F5 = 7:8; F6 = 7: 8; F7 = 9: 8; clava $=$ 22: 8 .

Mesosoma: Pronotum with distinct median groove, concave posteriomedially. Mesonotum with MLM distinctly longer than broad, $0.71 \mathrm{x}$ length of mesoscutum in dorsal view, a little convex, distinctly reticulate-punctate; LLM faintly reticulate, mostly shiny; dorsal margin not strong, with a fovea like cross depression; area beyond MLM between lateral lobes concave, smooth and with scattered pubescence; scutellar axillar complex well reticulate punctate; scutellum slightly convex. Prepectus subtriangular, smooth. Acropleuron with longitudinal striae. Macropterous; relative length of veins: $\mathrm{SMV}=48 ; \mathrm{MV}=52$; $\mathrm{PMV}=18 ; \mathrm{STV}=9$. Mid tibial spur a little shorter than mid basitarsus; mid tarsus with a single row of dark pegs on either side on basal four segments; hind basitarsus as long as following two segments combined.

Metasoma: A little longer than mesosoma (21: 18); tergites 
with $\mathrm{T} 1$ longest and sinuate in posterior margin at middle; T2 and T3 almost equal in length; T3 a little broader than T2; T4 a little longer and broader than T3; T5 broadest and shorter than T4. Ovipositor sheath slightly exserted posteriorly.

Variation: Length varies from 2-3 mm. The metallic green refringence on head and gaster weaker than that of holotype. In one specimen acropleuron a little darkish-brown.

Host: Unknown.

\section{Remarks}

A. yasumatsui Shafee resembles this new species in general appearance but differs in having MV not longer than SMV; eyes with sparse pubescence and the metallic green refringence spread on all mesoscutum.

\section{Anastatus (A.) ochirasis Narendran sp. nov.} (Figs. 44-47)

\section{Material examined.}

Holotype: Female, India: Kerala, Malappuram Dt., Calicut University Campus 2.1, $11^{\circ} 7^{\prime} \mathrm{N} \& 75^{\circ} 5^{\prime} \mathrm{E}$, 22.iii.1989, coll. T.C. Narendran, DZUC \# MoEF 1647.

\section{Etymology}

The species name is formed from the Greek words 'ochros' meaning pale yellow, indicating the pale yellow colour of the mesosoma and gaster.

\section{Description.}

Holotype: Female: Length $3 \mathrm{~mm}$.

Colour: Head with dark metallic green refringence; eye grayish yellow; ocelli pale reflecting yellow; antenna with scape, pedicel, anellus, F1- to F3 pale yellow, F4 pale yellowish-brown and F5-clava black; mandible brown with teeth darker; mesosoma pale yellow on pronotum, anterior part of mesoscutum, acropleuron and prepectus, but dark metallic green on remaining parts of mesoscutum and on scutellar axillar complex; legs pale yellow, with pretarsus dark brown; metasoma pale yellow with apical half of $\mathrm{T} 1$ and $\mathrm{T} 2$ completely pale

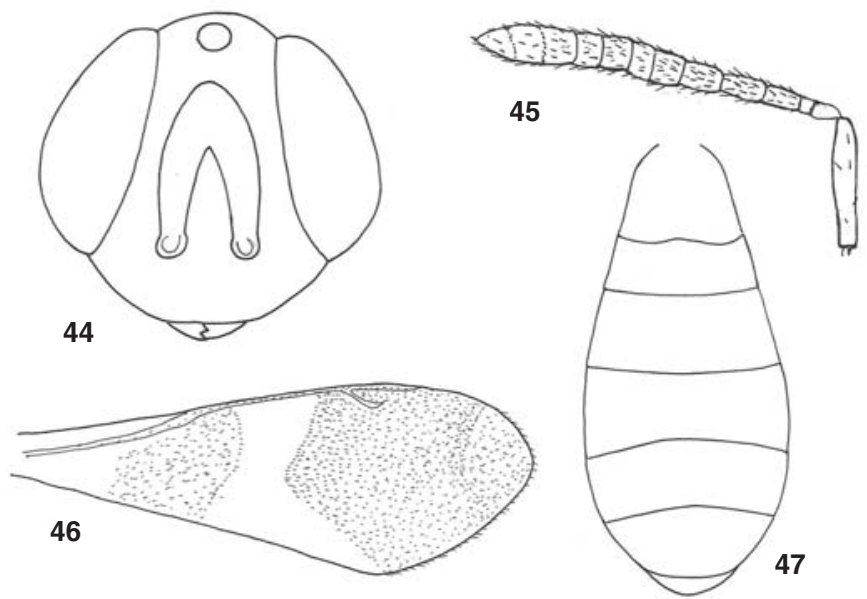

Figures 44-47. Anastatus ochirasis Narendran sp. nov. Female

44 - Head front view; 45 - Antenna; 46 - Forewing

47 - Metasoma dorsal view white. Forewing infumate with a hyaline band behind MV, outer margin of band accutr, base of forwing hyaline, apex les pigmed.

Head: A little wider than long high in anterior view (64: $61)$, reticulate; frons and face with moderately dense short white pubescence; MS 0.36x EH in profile; MG straight but weak; IAA convex, reticulate punctate; scrobe shallow, lateral margins carinate, separated from front ocellus a distance equal to diameter of front ocellus; scrobe reticulate; OOL: POL: LOL = 2: 3: 2. Relative measurements of $\mathrm{L}: \mathrm{W}$ of antennal segments: scape $=29: 5$; pedicel $=6: 4 ;$ anellus $=3: 3 ; \mathrm{F} 1=8: 4 ; \mathrm{F} 2=10$ : $5 ; \mathrm{F} 3=9: 6 ; \mathrm{F} 4=7: 8 ; \mathrm{F} 5=5: 8 ; \mathrm{F} 6=6: 8 ; \mathrm{F} 7=6: 8 ;$ clava $=22$ : 9 .

Mesosoma: Pronotum with a weak median line, shallowly concave posteromedially. Mesonotum with MLM slightly broader than long, 0.63x length of mesoscutum in dorsal view, finely reticulate punctate; LLM, finely reticulate with sharp dorsal margins, interspace between lateral lobes reticulate and depressed; mesoscutum with moderately dense pubescence on all sides, without forming rows; scutellar axillar complex moderately reticulate; scutellum convex. Prepectus subtriangular, weakly reticulate. Acropleuron weakly reticulate and with longitudinally arranged short sulci. Macropterous; relative length of veins: $\mathrm{SMV}=39 ; \mathrm{MV}=36$; $\mathrm{PMV}=15$; STV $=7$. Mid tibial spur a little shorter than mid basitarsus; mid tarsus with single row of dark pegs ventrally on either side on basal three segments; hind basitarsus as long as following three segments combined.

Metasoma: A little longer than mesosoma, gradually increasing in width from T1 to T4; (Fig. 47); T1 longer than T2; T3 about 1.4x median length of T2; T4 a little shorter than T3; T5 as long as T4. Ovipositor sheath not exserted beyond apex of gaster.

\section{Host: Unknown}

\section{Remarks}

This new species is based on a single specimen, but it is described here because it is unique in its antennal and forewing colour pattern.

\section{Anastatus (A.) operosus Narendran sp. nov.}

(Figs. 48-50)

\section{Material examined}

Holotype: Female, India: Kerala, Malappuram Dt., Calicut University Campus, $11^{\circ} 7^{\prime} \mathrm{N} \& 75^{\circ} 5^{\prime} \mathrm{E}, 10.1 \mathrm{i} .1989$, DZUC \# MoEF 1646.

\section{Etymology}

The species name taken from the Latin word 'operosus', meaning difficult, indicating difficulty in identifying the species.

\section{Description}

Female: Length $2.3 \mathrm{~mm}$.

Colour: Head dark brown with bronze refringence; eye pale yellow; ocelli brown; antenna dark brown with scape pale yellow; pronotum pale brownish-yellow with rim of spiracles dark brown with metallic green refringence; mesoscutum dark brown with bronze refringence on MLM and SAC; propodeum 

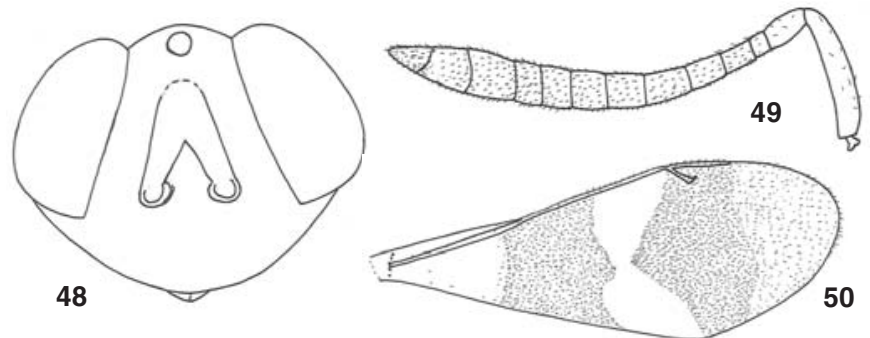

Figures 48-50. Anastatus operosus Narendran sp. nov. Female

48 - Head anterior view; 49 - Antenna; 50 - Forewing

dark brown on sides, pale brownish-yellow on median part; gaster black with T1 (mostly) pale yellow, sides of mesosoma including acropleuron pale brownish-yellow; legs pale yellowish-brown with bases and apices of mid and hind femur and tibia slightly paler. Forewing infumate with transeverse hyaline band below MV, outer margin of hyaline band acutely narrowed at middle(Fig. 50); area behind SMV hyaline.

Head: Wider than high in anterior view (88:70), strongly reticulate; IAA and area below IAA with moderately dense pubescence; MS 0.4x EH; MG straight; IAA slightly raised, convex, reticulate; scrobe shallow, lateral margins moderately carinate, separated from front ocellus by diameter of front ocellus; scrobal impression reticulate; OOL: POL: LOL $=1: 4$ : 3. Relative measurements of L: W of antennal segments: scape $=31: 6$; pedicel $=11: 6$; anellus $=4: 5 ; \mathrm{F} 1=7: 5 ; \mathrm{F} 2=9: 6 ; \mathrm{F} 3$ $=11: 7 ; \mathrm{F} 4=9: 8 ; \mathrm{F} 5=8: 9 ; \mathrm{F} 6=8: 9 ; \mathrm{F} 7=6: 10 ;$ clava $=31$ 10

Mesosoma: Pronotum with weak median groove, concave medially. Mesonotum with MLM as long as broad, 0.62x length of mesoscutum in dorsal view, a little convex, strongly reticulate-punctate, and sparsely pubescent; LLM smooth and shiny, without sharp dorsal margin, almost flat; area between lateral lobes behind MLM concave, faintly reticulate and sparsely pubescent; scutellar-axillar complex well reticulate; scutellum slightly convex. Prepectus subtriangular, weakly reticulate. Acropleuron granulate-reticulate. MacropterousS; relative length of veins: $\mathrm{SMV}=39 ; \mathrm{MV}=42 ; \mathrm{PMV}=16 ; \mathrm{STV}$ $=8$. Mid tibial spur a little shorter than mid basitarsus; mid tarsus with a single row of dark pegs on either side on basal four segments; hind basitarsus almost as long as following three segments combined.

Metasoma: Subequal to length of mesosoma; T1 longer than T2; T2 to T3 almost subequal in length; T5 broadest. Ovipositor sheath hardly exserted posteriorly.

\section{Host: Unknown.}

\section{Remarks}

This species may be likely to get misidentified on two accounts: careful observation is necessary to note that the hyaline band really reaches the junction of MV and STV and the acute portion of the outer margin of the hyaline band does not actually touch the posterior margin of the band deviding the band into two. Hence the name operosus.

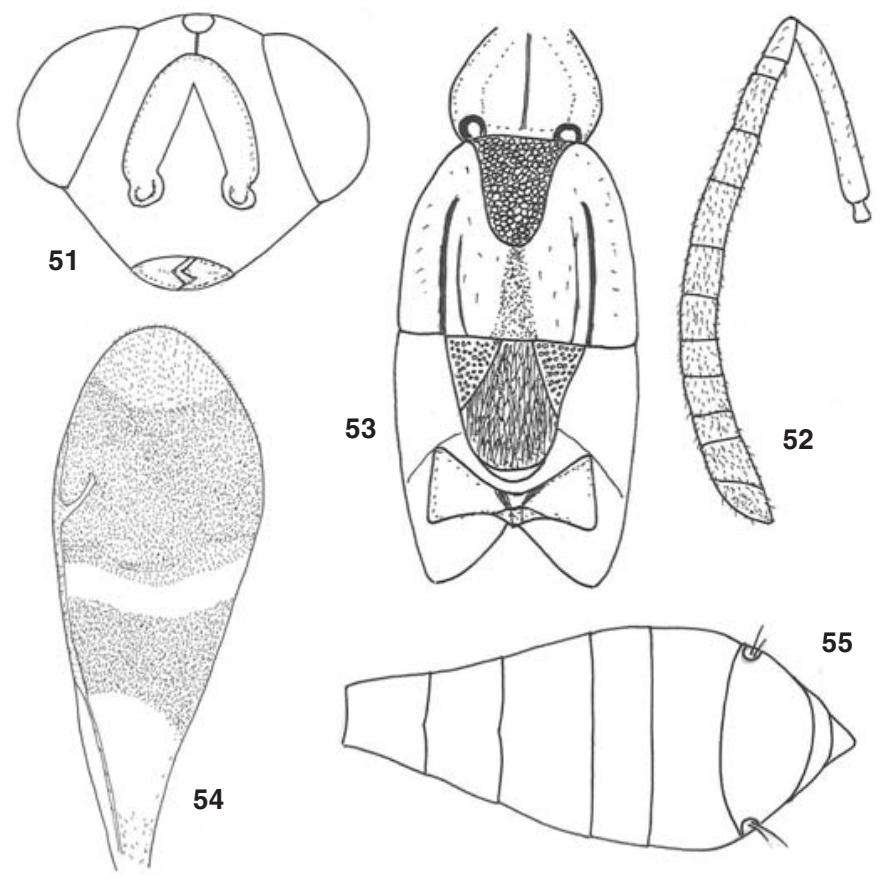

Figures 51-55. Anastatus phaeonotus Narendran sp. nov. Female

51 - Head front view; 52 - Antenna; 53 - Mesosoma dorsal view; 54 - Forewing; 55 - Metasoma dorsal view

\section{Anastatus (A.) phaeonotus Narendran sp. nov.}

(Figs. 51-55)

\section{Material examined.}

Holotype: Female, India: Kerala, Alappey Dt., Kayamkulam, Onattukara, $9^{\circ} 10^{\prime} \mathrm{N} \& 76^{\circ} 30^{\prime} \mathrm{E}, \mathrm{RRS}, 19 . \mathrm{iv} .2004$, coll. T.C. Narendran \& Party, DZUC \# MoEF 7.

Paratypes: 11 females, India: Kerala, Alappey, Kayamkulam, $8^{\circ} 5^{\prime} \mathrm{N} \& 77^{\circ} 31^{\prime} \mathrm{E}, 20.11 .1989$, coll. Anil, K (3); Kerala, Thrissur Dt., Peechi $10^{\circ} 31^{\prime} \mathrm{N} \& 7^{\circ} 13{ }^{\prime} \mathrm{E}$, 5.ii.1989, coll. T.C. Narendran \& Party (2); Kerala, Thrissur Dt., Vazhani $10^{\circ} 38^{\prime} \mathrm{N} 76^{\circ} 19^{\prime} \mathrm{E}$, 8.ii.1989, coll. T.C. Narendran \& Party (1); Kerala, Palghat Dt., Malampuzha, $10^{\circ} 53^{\prime} \mathrm{N} \& 76^{\circ} 46^{\prime} \mathrm{E}$, 4.i.1986, coll. T.C. Narendran \& Party (1); Kerala, Malappuram Dt., Calicut University Campus, $11^{\circ} 7^{\prime} \mathrm{N} \& 75^{\circ} 5^{\prime} \mathrm{E}$, 16.iv.1989, coll. K. Anil (2); Kerala, Malappuram Dt., Calicut University Campus, $11^{0} 7^{\prime} \mathrm{N} \& 75^{\circ} 5^{\prime} \mathrm{E}, 28.1 i .1985$ coll. T.C. Narendran (1); Kerala, Malappuram Dt., Kadakattupara (near Calicut University Campus), $11^{\circ} 7^{\prime} \mathrm{N} \& 75^{\circ} 5^{\prime} \mathrm{E}, 9 . i \mathrm{i} .1988$, coll. T.C. Narendran (1).

\section{Etymology}

The species name is formed from the Greek words 'phaios', meaning dusky brown, and 'notos', meaning back, indicaating the colour of the notum of the mesosoma.

\section{Description}

Holotype: Female: Length $2.8 \mathrm{~mm}$.

Colour: Head black with metallic green refringence on gena, temples, scrobe and face; eye brown with margins around paler; ocelli pale reflecting yellow; scape pale brownish-yellow; pedicel dark brown with metallic green refringence; remaining antennal segments dark brown; pronotum pale yellowish-brown 
with posterior spiracular area black; mesoscutum yellowishbrown with slight metallic green refringence on LLM and area posterior to MLM; scutellar-axillar complex blackish-brown; metanotum pale yellowish-brown; propodeum brown; gaster brown except T2 and apical marginal area of T1 pale white. Legs yellowish-brown with apex of mid tibia, mid tibial spur, mid tarsus, and basal 3 tarsal segments of hind tarsus pale yellow. Forewing with two broad infumated area separated from each other by a hyaline cross band behind MV, outer margin of hyaline band gently curving (Fig. 54), base of forewing behind SMV hyaline; apex of wing less pigmented.

Head: Wider than high in anterior view (72: 57), coarsely reticulate; frons and face with short white pubescence; MS $0.45 \mathrm{x}$ $\mathrm{EH}$ in profile; MG straight; IAA convex and strongly reticulate; scrobe shallow, lateral margins carinate; scrobe separated from front ocellus by diameter of front ocellus; scrobe reticulate; front ocellus connected to scrobe by a median sulcus; OOL: POL: $\mathrm{LOL}=1: 4: 3$. Relative measurement of $\mathrm{L}: \mathrm{W}$ of antennal segments: scape $=36: 5$; pedicel $=8: 5$; anellus $=4: 5 ; \mathrm{F} 1=11$ : $5 ; \mathrm{F} 2=10: 6 ; \mathrm{F} 3=12: 6 ; \mathrm{F} 4=9: 7 ; \mathrm{F} 5=8: 7 ; \mathrm{F} 6=7: 7 ; \mathrm{F} 7=$ 7: 7 ; clava $=25: 8$.

Mesosoma: Pronotum with distinct median groove, moderately concave posteromedially. Mesonotum with MLM a little longer than broad (17: 15), 0.53x length of mesoscutum in dorsal view, finely reticulate; LLM weakly reticulate, shiny, with sharp dorsal margin; interspace between dorsal margins of lateral lobes shallowly concave, smooth and shiny; mesoscutum sparsely pubescent; scutellar axillar complex strongly reticulate; scutellum moderately convex. Prepectus subtriangular, faintly reticulate, mostly smooth and shiny. Acropleuron faintly reticulate. Macropterous; relative length of veins: $\mathrm{SMV}=42 ; \mathrm{MV}=42 ; \mathrm{PMV}=15 ; \mathrm{STV}=9$. Midtibial spur shorter than basitarsus; mid tarsus with single row of dark pegs ventrally on either side on basal three segments; hind basitarsus subequal to following three segments combined.

Metasoma: Longer than mesosoma (13: 10); T1 as long as T2,posterior margin slightly sinuate; T2 shorter than T3 ,posterior margin slightly sinuate; T3 longer than T1 or T2 ; T4 shorter than T5; T4 and T5 broadest. Ovipositor sheath very slightly exserted.

Variation: Length varies from 2.5-2.8mm. The metallic refringence is weak in some specimens.

\section{Hosts: Unknown}

\section{Remarks}

This new species can be confused with $A$. bifasciatus (Geoffroy) but A.bifasciatus differs from this new species in having metallic green refringence on LM; metasoma distinctly shorter than $2 \mathrm{x}$ its width, and MLM relatively much longer than that of $A$. phaonotus.

\section{Anastatus (A.) quilonicus Narendran sp. nov.} (Figs. 56-57)

\section{Material examined}

Holotype: Female, India: Kerala, Ouilon Dt., Santhamkottai, and 12.vii.2004. coll. T.C. Narendran, DZUC \# MoEF 1648.

\section{Etymology}

The species is named after the district Quilon from where

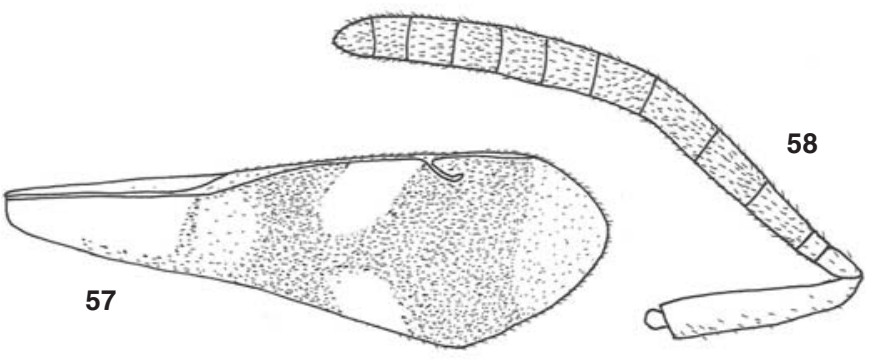

Figures 56-57. Anastatus quilonicus Narendran sp. nov. Female

56 - Antenna; 57 - Forewing

the holotype is collected.

\section{Description}

Female: Length $4.27 \mathrm{~mm}$

Colour: Black with following parts as follows: scape pale yellow; frons, gena, scrobe and MLM with bronze refringence (seen only under certain angles of illumination); tegulae and prepectus pale yellowish-brown; base of metasoma pale yellowish-white; pronotum pale brownish-yellow with spiracular rim black; eye gray, ocelli pale reflecting yellow; legs dark brown with paler strips, mid and hind tarsi pale yellow; pegs of mid tarsus black; wings infumate with two hyaline patches (Fig. 57) one below the other behind MV,. With a pale bown patch below parastigma and a hyaline area behind SMV.

Head: A little wider than high in anterior view (19: 17); width in dorsal view $2.5 \mathrm{x}$ dorsal length between anterior (outer) distal margin of front ocellus and occipital margin; frons, vertex, face and gena distinctly reticulate, with moderately dense white pubescence on face and IAA; MS 0.29x EH; MG slightly curved towards posterior side; IAA convex, coarsely reticulate; scrobe deep, reticulate, side margins carinate, separated from front ocellus by diameter of front ocellus, connected to front ocellus by a shallow fovea; front ocellus separated from eye by diameter of front ocellus; OOL:POL:LOL = 2:6:3. Relative measurements of L:W of antennal segments: scape $=35: 7$; pedicel $=8: 6$; anellus $=4: 5 ; \mathrm{F} 1=12: 5 ; \mathrm{F} 2=12: 7 ; \mathrm{F} 3=14: 7 ; \mathrm{F} 4=10: 8$; $\mathrm{F} 5=9: 8 ; \mathrm{F} 6=8: 8 ; \mathrm{F} 7=8: 8 ;$ clava $=21: 8$.

Mesosoma: Pronotum with a median groove, concave posteromedially. Mesonotum with MLM longer than broad (11:7), 0.73x length of mesoscutum in dorsal viw, moderately pubescent, convex, well reticulate; LLM faintly reticulate, with sharp raised dorsal margin on posterior half; scutellar-axillar complex punctate; scutellum convex. Prepectus subtriangular, weakly reticulate. Acropleuron longitudinally striatereticulate. Macropterous; relative length of veins: $\mathrm{SMV}=42$; $\mathrm{MV}=40 ; \mathrm{PMV}=20 ; \mathrm{STV}=7$. Midtibial spur little longer than mid basitarsus (15: 14); midtarsus with a single row of dark pegs ventrally on either side on basal four segments; hind basitarsus a little shorter than combined length of following three segments combined.

Metasoma: Subequal to or a trifle longer than mesosoma (16: 15); T1 longest, its posterior margin sinuate at middle; T2 shorter than T3 and almost equal to T5; T3 longer than T4; T5 shorter than T4; T6 convex at posterior margin. Ovipositor sheath not exserted. 


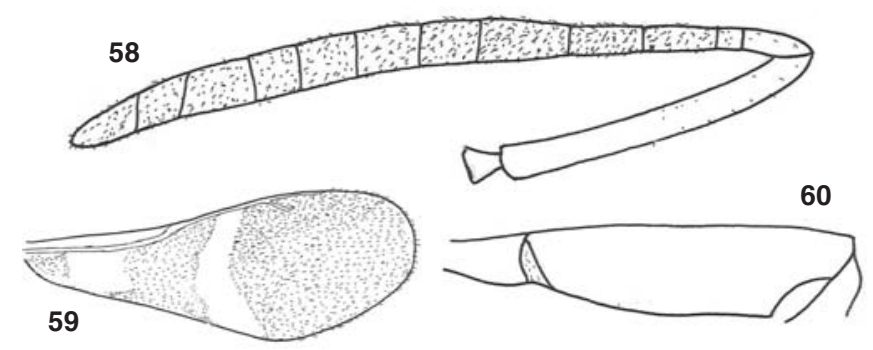

Figures 58-60. Anastatus ramakrishnai (Mani). Female 58 - Antenna; 59 - Forewing; 60 - Forefemur

Host: Unknown.

\section{Remarks}

This species comes near $A$. acherontiae in general appearance but differs in having: forewing from base of its insertion below tegula never reaches apex of metastoma and body without metallic green refringence.

\section{Anastatus (A.) ramakrishnai (Mani)}

(Figs. 58-60)

Neanastatus ramakrishnai Mani, 1935: 255. Female, India, Howrah (ZSI).

Anastatus ramakrishnai (Mani); Hayat, 1975: 263.

Anastatus dentatus Narayanan, Subba Rao \& Ramachandra Rao, 1960: 173. Female (holotype), male, INDIA, New Delhi (lost?) Syn. Nov.

\section{Material examined}

39 females, India: Kerala, Alappey Dt., Kayamkulam, CPCRI, 9 ${ }^{\circ} 10^{\prime} \mathrm{N} \& 76^{\circ} 30^{\prime} \mathrm{E}, 10 . \mathrm{v} .1999$, emerged from Pentatomid eggs, coll. Chandrika Mohan (22); Kerala, Malappuram Dt., Calicut University Campus, $11^{\circ} 7^{\prime} \mathrm{N} \& 75^{\circ} 5^{\prime} \mathrm{E}$, 8.ix.2001, coll. T.C. Narendran \& Party (1); Malappuram Dt., Calicut University Campus, $11^{\circ} 7^{\prime} \mathrm{N} \& 75^{\circ} 5^{\prime} \mathrm{E}$, Feb. 1980, coll. T.C. Narendran \& Party (1); Kerala, Malappuram Dt., Nilambur, $11^{\circ} 16^{\prime} \mathrm{N} \& 76^{\circ} 14^{\prime} \mathrm{E}$, 1.v.1982, coll. T.C. Narendran \& Party (10); Himachal Pradesh, Mandi Gutkar, 22.vi.2006, coll. S.M.A. Badruddin \& F.R. Khan (2); Tamil Nadu, Chennai, 3.viii.2003, Paul Raj (1); Uttar Pradesh, Saranpur, 25.vii.1983, S.C. Dehiman (1); Kerala, Malappuram Dt., Calicut University Campus, $11^{\circ} 7^{\prime} \mathrm{N} \& 75^{\circ} 5^{\prime} \mathrm{E}, 11 . i v .1989$, coll. K. Anil (1).

\section{Description}

Female: Length 2.5-3.18mm. Body dark brown to black, in part metallic; head bluish-green and bronzy, the latter more intense on frontovertex; scape yellowish-brown, rest of antenna dark brown; dorsum of mesosoma black with bronze refringence except concave area behind MLM with bluish-green or green refringence; pronotum black with bluish violet refringence (in some specimens pronotum yellowish-brown with spiracular rim black); scutellar axillar complex black; prepectus usually black with basal part brown, but in some specimens mostly yellowishbrown; acropleuron black or in some specimens brown with apical part black; metanotum and propodeum black or dark brown; legs dark brown or in a few specimens brown to lighter brown, but with bases and apices of tibiae, and tarsi slightly less dark (in one specimen tarsi pale); pegs of mid tarsus black. Forewing infumate with a hyaline cross band behind MV and another hyaline part below SMV (Fig. 57); outer margin of hyaline band behind MV not acutely bend but only slightly curved; hyaline band not extending to junction of MV and STV.

Head: wider than high in anterior view, reticulate; IAA and ventral half of frons with moderate dense pilosity. MS 0.33$.35 \mathrm{x}$ EX in side view; MG curved at middle towards posterior side; IAA moderately convex, reticulate, with moderately dense pubescence; scrobe not deep, channel like, reticulate, posteriorly shallow, lateral margins carinate, separated from front ocellus by a distance a little more than diameter of front ocellus; OOL:POL:LOL = 1:4:3. Relative measurements of $\mathrm{L} ; \mathrm{W}$ of antennal segments: scape $=37: 4$; pedicel $=8: 3$; anellus $=$ $3: 2 ; \mathrm{F} 1=8: 3 ; \mathrm{F} 2=8.5: 3 ; \mathrm{F} 3=10: 5 ; \mathrm{F} 4=7: 5 ; \mathrm{F} 5=7: 5 ; \mathrm{F} 6=7: 5$; $\mathrm{F} 7=5: 5 ;$ clava $=22: 5$.

Mesosoma: Pronotum with distinct median groove, concave medially. Mesoscutum with MLM distinctly longer than broad, $0.65-0.67 x$ length of mesoscutum in dorsal view, with raised reticulations; LLM distinctly reticulate (weakly reticulate in some specimens from Kerala), posteriorly with moderately raised dorsal margin; area beyond MLM and between LLM moderately concave, smooth and shiny with sparse or no pubescence. SAC with raised reticulation; scutellum slightly convex. Prepectus subtriangular, weakly reticulate. Acropleuron distinctly reticulate. Macropterous; relative lengths of forewing veins: $\mathrm{SMV}=26 ; \mathrm{MV}=19 ; \mathrm{PMV}=9.5$; $\mathrm{STV}=4$. Fore femur with a distinct subapical tooth(Fig.58); midtibial spur equal in length of midbasitarsus; hindbasitarsus almost as long as following 3 segments combined.

Metasoma: slightly shorter than mesosoma; T1 longest, its posterior margin sinuate at middle; T2 to T5 subequal in length and with posterior margins slightly sinuate at middle; T4 broadest; T6 convex posteriorly.

Variation: The metallic green refringence on head and area between LLM vary from weak to strong. In a few specimens T3 longer than $\mathrm{T} 2$ or $\mathrm{T} 4$ and sinuation of posterior margins of $\mathrm{T} 3$ to T5 not distinct. Rarely metasoma is almost equal to mesosoma in a few specimens.

Male: For description see Hayat (1975).

\section{Distribution}

INDIA (Maharashtra, Uttar Pradesh, West Bengal, Delhi, Bihar, Kerala (new record), Tamil Nadu (new record).

\section{Host}

Lepidopterous eggs on Annona squamosa L. (Annonaceae) (Hayat, 1975) and eggs of Halys dentata Fabricius and Tessaratoma javanica (Thumb.) (Heteroptera: Pentatomidae) (Narayanan et al. 1960).

\section{Remarks}

The description of $A$. dentatus clearly shows that it is conspecific with $A$. ramakrishnai, as first suggested by Hayat (1975). The African Anastatus axiagasti Ferriere comes very near to A.ramakrishnai but A. ramakrishnai differs in having pedicel length more than one-fourth of scape, F1 more than $2 \mathrm{x}$ as long as wide; clava distinctly not shorter than combined length of three preceeding segments. 


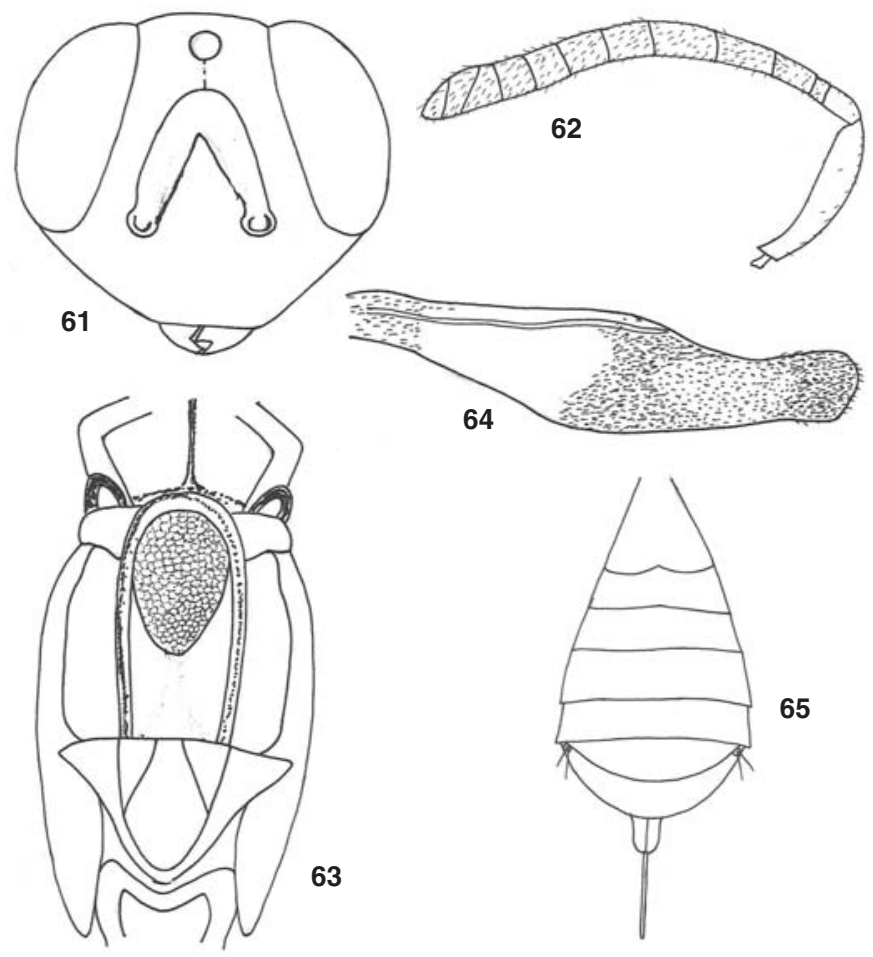

Figures 61-65. Anastatus rufopostumus Narendran sp. nov. Female

61 - Head front view; 62 - Antenna; 63 - Mesosoma dorsal view; 64 - Forewing; 65 - Metasoma dorsal view

\section{Anastatus (A.) rufopostumus Narendran sp. nov.}

(Figs. 61-65)

\section{Material examined}

Holotype: Female, India: Kerala, Thrissur, $10^{\circ} 28^{\prime} \mathrm{N} \&$ $76^{\circ} 18^{\prime} \mathrm{E}, 4 . x i i .1988$, coll. T.C. Narendran \& Party, DZUC \# MoEF 1643 .

Paratypes: 4 females, India: Kerala, Palghat Dt., Silent Valley, $11^{\circ} \mathrm{O} 4^{\prime} \mathrm{N} \& 7^{\circ} 79^{\prime}$ E, 9.xii.1987, coll. T.C. Narendran \& Party (1); Kerala, Wayanad Dt., Muthanga, $11^{\circ} 12^{\prime} \mathrm{N} \& 76^{\circ} 15^{\prime} \mathrm{E}$, 7.x.1985, coll. T.C. Narendran \& Party (1); Kerala, Malappuram Dt., Calicut University Campus, $11^{\circ} 7^{\prime} \mathrm{N} \& 75^{\circ} 5^{\prime} \mathrm{E}, 22$. iii. 1989 (2).

\section{Etymology}

The species name is taken from the Latin words 'rufo', meaning red, and 'postumus', meaning hindmost, indicating red colour of $\mathrm{T} 7$.

\section{Description}

Holotype: Female: Length $3.3 \mathrm{~mm}$. Head black with slight coppery refringence on frons; occiput, temple, gena and face below toruli metallic green; eye gray; ocelli dark brown; antenna dark brown with scape pale yellowish-brown; pronotum yellow with spiracular part black; mesoscutum pale yellowish-brown; scutellar axillar complex dark brown; propodeum black; prepectus pale yellow; acropleuron yellowish-brown; legs dark brown with fore and mid coxae lighter brown, mid tarsus pale yellow with pegs black and fore and hind tarsus pale brownishyellow; gaster with T1 and T2 whitish-yellow; T3 to T6 dark brown, T7 reddish-brown. Wings infumate with hyaline patch below SMV (except base); distal infumate part of forewing with a lighter yellowish pigmented area medially.

Head: A little wider than high in anterior view (68: 63), distinctly reticulate; frons, face and gena with moderately dense white pubescence; MS $0.33 \mathrm{x}$ EH in profile; MG slightly bent posteriorly before joining lower margin of MS; IAA coarsely reticulate; scrobe deep, lateral margins carinate, separated from front ocellus by diameter of front ocellus; scrobal impression cross reticulate; front ocellus connected to scrobe by a weak groove (Fig. 61); OOL:POL:LOL = 2:3:2.5. Relative measurements of L:W of antennal segments: scape $=35: 7$; pedicel $=10: 5$; anellus $=3: 4 ; \mathrm{F} 1=10: 5 ; \mathrm{F} 2=12: 6 ; \mathrm{F} 3=13: 7$; $\mathrm{F} 4=10: 7 ; \mathrm{F} 5=9: 7 ; \mathrm{F} 6=7: 8 ; \mathrm{F} 7=7: 8 ;$ clava $=18: 9$.

Mesosoma: Pronotum with distinct median groove; concave postero-medially. Mesonotum with MLM distinctly longer than broad, $0.57 \mathrm{x}$ length of mesoscutum in dorsal view, not strongly convex, nearly flat, distinctly reticulate; LLM smooth and shiny, with sharp raised dorsal margin on anterior and posterior halves, MLM sparsely pubescent; area between lateral lobe behind MLM depressed, smooth and shiny with pubescence; scutellaraxillar complex moderately reticulate; scutellum slightly convex. Prepectus subtriangular, weakly reticulate. Acropleuron finely and longitudinally striate reticulate. Brachypterous. Forwing extending not beyond posterior margin of T1. Mid tibial spur subequal to mid basitarsus; mid tarsus with single row of black pegs ventrally on either side on basal three tarsal segments; hind basitarsus a little longer than following three segments (but shorter than following 4 segments) combined.

Metasoma: A little longer than mesosoma (13: 11),1.8x as long as broad; T1 $1.75 \mathrm{x}$ as long as T2; T3 slightly longer than T2 and slightly broader than T2; T4 slightly longer and broader than T3; T5 broadest and shorter than T4; T6 and T7 narrower than T5 (Fig. 65). Ovipositor sheath exserted (Fig. $35)$.

Variation: Length $2.6-3.3 \mathrm{~mm}$. Acropleuron more yellowish brown and head_with slight metallic refringence in some specimens. MLM 0.57 to $0.64 x$ length of mesoscutum.

Host: Unknown.

\section{Remarks}

This species can be confused with $A$. hayati in general features but can be easily distinguished in having $\mathrm{T} 7$ reddishbrown, non-pointed clava, relatively longer scape scape, and different colour patterns.

\section{Anastatus (A.) tenuipes Bolivar}

(Figs. 66-67)

Anastatus tenuipes Bolivar y Pieltain, 1925: 43. Female, Egypt (USNM).

Anastatus blattidarum Ferrière, 1930: 33. Female, Sudan (BMNH) (examined). Synonymy by Ferrière 1960: 246.

Solindenia blattiphagus Mani, 1936: 131. Female, male (holotype), India (ZSI). Synonymy by Ferrière 1938: 84.

Anastatus Wanei Risbec, 1951. Female, Senegal (MNHN). Synonymy by Boucek 1976: 350.

\section{Material examined}

25 females, Holotype of $A$. blattidarum Ferriere.Sudan (Khartoum) (BMNH \# Hym.5: 1017); India: Uttar Pradesh,

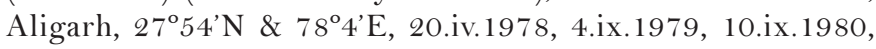




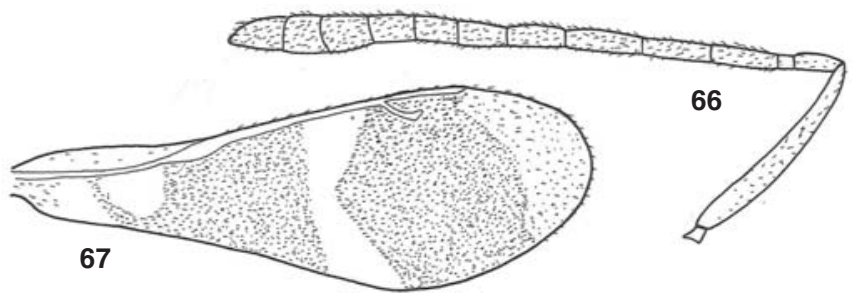

Figures 66-67. Anastatus tenuipes Bolivar Female 54 - Antenna; 55 - Forewing

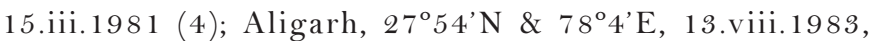
28.viii.1983, 5.viii.1983, 11.vii.1983, 29.ix.1983, 20.viii.1984, 21.vii.1983 (20).

\section{Redescription}

Female: Length 2.5-3.5mm. Body brownish-yellow to brown or black with reddish-blue refringence; head green with coppery refringence; scape pale yellow or yellowish-brown; pedicel pale yellow or dark brown; rest of antenna black or dark brown; mesosoma lemon brown with black infuscation; pronotum with spiracular rim black; mesoscutum with posterior half with purple violet refringence; legs brown with some infuscation in part; tarsal segments yellowish-brown or pale white; distal part of $\mathrm{T} 1$ and $\mathrm{T} 2$ completely white, rest of segments black. Forewing infumate with basal part and a curved cross band below MV hyaline; hyaline band not extending upto junction of MV and STV.

Head: wider than high in anterior view, reticulate; IAA and ventral half of frons with sparse white hairs. MS 0.60-0.63 $\mathrm{EH}$ in side view; MG curved at middle towards posterior side; IAA convex, distinctly reticulate; scrobe shallow, channel like, lateral margin carinate, separated from front ocellus by about one ocellar or half ocellar diameter of front ocellus; scrobe reticulate, connected to front ocellus by a narrow depression; OOL: POL:LOL = 5:20:10. Relative measurements of L:W of antennal segments: scape $=30: 3$; pedicel $=7: 2$; anellus $=2: 2$; $\mathrm{F} 1=9: 3 ; \mathrm{F} 2=10: 2 ; \mathrm{F} 3=11: 3 ; \mathrm{F} 4=8: 3 ; \mathrm{F} 5=7: 3 ; \mathrm{F} 6=6: 3 ; \mathrm{F} 7$ $=6: 4 ;$ clava $=20: 5$.

Mesosoma: Pronotum with distinct median groove, concave posteriormedially. Mesoscutum with MLM distinctly longer than broad, 0.64-0.67x length of mesoscutum in dorsal view, convex, with moderately raised reticulation; LLM weakly reticulate, posteriorly with sharp raised dorsal margin; area beyond MLM and between LLM weakly concave, mostly smooth and shiny with very sparse or no pubescence. SAC very strongly reticulate-punctate; scutellum slightly convex. Prepectus subtriangular, shiny. Acropleuron longitudinally striate-reticulate. Macropterous; relative lengths of forewing veins: $\mathrm{SMV}=36 ; \mathrm{MV}=31 ; \mathrm{PMV}=15 ; \mathrm{STV}=7.5$. Midtibial spur a little shorter than midbasitarsus; midtarsus with a single row of dark pegs ventrally on either side on basal three segments (in some specimens a dark peg on either side at distal ventral margin of $4^{\text {th }}$ tarsal segment present); hind basitarsus almost equal to combined length of following 3 segments.

Metasoma: as long as or a little longer than mesosoma; T1 longest, posterior margin incised at middle; T2 shorter than T3; T4 and T5 subequal in length to T3; T6 convex posteriorly, $\mathrm{T} 7$ and $\mathrm{T} 5$ subequal in length to T3; T6 convex posteriorly, T7 with slightly upturned rim at apex.
Variation: already provided in the text above.

Male: For description see Ferriere (1935) and Hayat (1975).

\section{Destribution}

India (Karnataka, RajasthanUttar Pradesh, West Bengal,). Also distributed in Europe, Africa and Americas (For details Noyes 2003).

Host

Periplaneta americana L.and Blattia spp. ootheca (Blattaria: Blattidae); Phyllodromia sp., Supella longipalpa (F.) and Supella supellectilium (Serville) (Blattaria: Blattellidae) (Noyes 2003).

\section{Remarks}

A. Blattidifurax Girault, which is known to attack ootheca of a cockroach from Queensland, Australia differs from $A$. tenuipes in having: 1) F7 a little wider than long (longer than wide in $A$. tenuipes); 2) F7 Shorter than half length of F1 (F7 not shorter than half length of $\mathrm{F} 1$ in $A$. tenuipes); 3) Body dark metallic blue (in $A$. tenuipes body mostly yellowish-brown or brown with reddish-blue refringence and head with metallic green refringence); 4) Hyaline band curved (hyaline band angulated in most female $A$. tenuipes).

\section{Anastatus (A.) yasumatsui Shafee}

Anastatus yasumatsui Shafee, 1973: 135. Female India, Bangalore (ZDAMU).

\section{Material Examined}

3 females, India: Kerala, Panayathamparamba (Near Kannur Airport), $11^{\circ} 54^{\prime} 32 \mathrm{E} \& 75^{\circ} 30^{\prime} 27 \mathrm{~N}$, Agri. Field, 23.xii.2007, coll. N.K. Seena (1); Kerala, Alappey Dt., Kayamkulam, 9 ${ }^{\circ}{ }^{\prime} \mathrm{N} \& 76^{\circ} 30^{\prime} \mathrm{E}, 20 . i i .1989$, coll. T.C. Narendran (1); Karnataka, Karwar, 12.x.2001, coll. Raji (1).

Distribution: India (Karnataka and Kerala (new record for Kerala))

\section{Redescription}

Female: Length $3.1 \mathrm{~mm}$. Head metallic with reddish-green refringence; radicle and scape brownish, remaining antennal segments dark; mesosoma metallic with bluish-green refringence; forewing infuscate with two hyaline patches below $\mathrm{MV}$; hyaline patch not touching junction of MV and STV; base of forewing slightly infuscated but area behind anterior threefourths of SMV hyaline; apical part of forewing not very distinctly separated by weaker pigmentation. Metasoma dark with metallic refringence and basal segment yellow. Eyes with sparse pubescence.

Head: A little wider than long in anterior view, reticulate;IAA and ventral half of frons coarsely reticulate and with moderately dense pilosity; IAA broadly convex with raised median longitudinal carina at base; eyes very sparsely pubescent; MS 0.33-0.35x EH in side view; MG slightly curved at middle towards posterior side; scrobe moderately deep channel like, posteriorly slightly shallower than anteriorly, lateral margins carinate, separated from front ocellus by a diameter of front ocellus (or by slightly longer distance), connected to front ocellus by a distinct groove; OOL:POL:LOL $=2: 6: 3$. Relative measurements of $\mathrm{L}: \mathrm{W}$ of antennal segments 
$:$ scape $=27: 5 ;$ pedice $=6: 3 ;$ anellus $=2: 3 ; \mathrm{F} 1=8: 3.5 ; \mathrm{F} 2=8: 4$; $\mathrm{F} 4=8: 4 ; \mathrm{F} 4=7: 5 ; \mathrm{F} 5=6: 6 ; \mathrm{F} 6=5: 6 ; \mathrm{F} 7=5: 7 ;$ clava $=17: 7$.

Mesosoma: Pronotum with distinct median groove, concave posteriormedially. Mesonotum with MLM longer than broad, $0.58 \mathrm{x}$ length of mesoscutum in dorsal view, convex, distinctly raised reticulation; LLM distinctly reticulate, dorsal margin raised sharply on posterior half; area beyond MLM and between LLM deeply concave, smooth and shiny, with very sparse pubescence; SAC similarly sculptured as MLM; scutellum convex. Prepectus subtriangular, faintly reticulate. Acropleuron striate-reticulate. Macropterous; relative lengths of forewing veins: $\mathrm{SMV}=20 ; \mathrm{MV}=22 ; \mathrm{PMV}=9 ; \mathrm{STV}=4$. Midtibial spur as long as (slightly longer in one specimen) midbasitarsus; midtarsus with a row of black pegs on either side ventrally on basal three segments; hindbasitarsus as long as following three segments combined.

Metasoma: longer than mesosoma; T1 longer than T2, its posterior margin sinuate at middle; $\mathrm{T} 2$ to $\mathrm{T} 4$ subequal in length; T5 slightly shorter than T4; T4 broadest.

Variation: In original description midtibial spur is stated to be a little shorter than midbasitarsus; scape $\mathrm{L}: \mathrm{W}=27: 3$. Other variations are metioned in the text above.

\section{Host}

Ooetheca of unidentified cockroach on Acacia arabica (Lam.) (Fabaceae).

\section{Remarks}

$A$. amarus and $A$. cherontiae come very near $A$. yasumatsui in general appearance but $A$. yasumatsui differs from these species in having: the hyaline spot behind MV not extending to junction of MV and STV; eyes without puescence and hind basitarsus as long as following two segments combined.

\section{Anastatus (Cladanastatus) madagascariensis (Risbec)}

(Fig. 68)

Oodera madagascariensis Risbec, 1952: 143, Madagascar (MNHN).

Ooderella madagascariensis (Risbec); Hedqvist, 1970: 441 new combination.

Anastatus (Cladanastatus) madagascariensis (Risbec); Bouček, 1988: 550.New combination

Anastatus (Cladanastatus) umae Bouček, 1979: 93, female (holotype), India, Kambalpalli (BMNH). Synonymized with A. madagascariensis by Bouček, 1988: 550 .

\section{Material examined}

None.

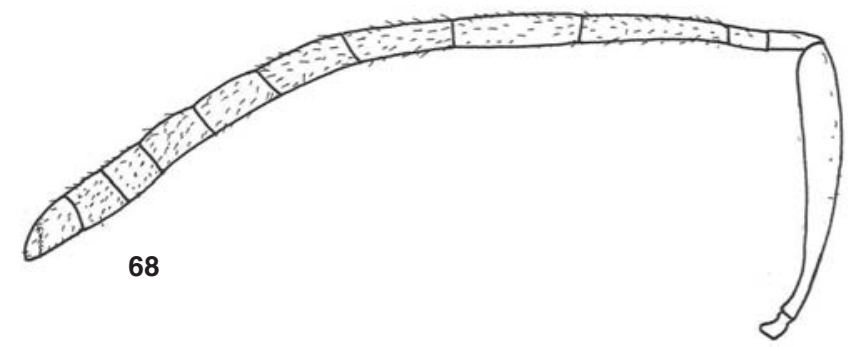

Figure 68. Anastatus madagascariensis (Risbec) Female 68 - Antenna
Distribution: India (Andhra Pradesh, Karnataka).

Diagnosis (based on Boucek 1979 and Gibson 1995)

Blackish-purple with violaceous gloss in certain places. Head relatively flat menuscoidal with black setae; MLM reddish-purple; antennae (Fig. 68) relatively long with F1 conspicously longer than clava, more than $2 \mathrm{x}$ as long as pedicel; forewing extensively infuscate in distal two-thirds, paler only below marginal vein (Bouček 1979, Fig. 18) and at apical margin, basal third subhyaline but with infuscate area at base, a curved streak below end of basal cell and fuscus streak on middle of SMV.

\section{Male}

Antenna with $\mathrm{F} 1$ to $\mathrm{F} 4$ relatively short and each with a dorsal ramus; F5 as long as the ramus of F4 (Boucek 1979, Fig. $21)$.

\section{Host}

Ootheca of Neostylopyga rombifolia (Stoll.) and Periplaneta americana (Linn.) (Blattaria: Blattidae).

\section{REFERENCES}

Ashmead, W.H. (1896). On the genera of the Eupelminae. Proceedings of the Entomological Society of Washington 4: 4-20.

Ashmead, W.H. (1904). Descriptions of new Hymenoptera from Japan. II. Journal of the New York Entomological Society 12(3): 153.

Bhatnagar, S.P. (1952). Descriptions of new and records of known Chalcidoidea (Parasitic Hymenoptera) from India. Indian Journal of Agricultural Science 21: 155-178.

Bolivary Pieltain, C. (1925). Sur quelques Eupelmidae de l' Egypte (Hym. Chalcidiens). Bulletin de la Société Royale Entomologie d'Egypte 9: 3945

Boucek, Z. (1970). Contribution to the knowledge of Italian Chalcidoidea based mainly on a study at the Institute of Entomology in Turin, with descriptions of some new European species (Hymenoptera). Memorie della Società Entomologica Italiana 49: 35-102.

Boučk, Z. (1974). On the Chalcidoidea (Hymenoptera) described by C. Rondani. Redia 55: 241-285.

Boucek, Z. (1976). Changes in the classification of some African Chalcidoidea (Hymenoptera). Journal of the Entomological Society of Southern Africa 39(2): 345-355.

Boucek, Z. (1979). Description of a new eupelmid parasite (Hymenoptera: Chalcidoidea) of cockroaches in India. Bulletin of Entomological Research 69(1): 93-96.

Boucek, Z. (1988). Australasian Chalcidoidea (Hymenoptera). A Biosystematic Revision of Genera of Fourteen Families, with a Reclassification of Species. CAB International, Wallingford, Oxon, U.K., Cambrian News Ltd; Aberystwyth, Wales, 832pp.

Brèthes, J. (1922). Hyménopteros y Dípteros de Varias procedencias. Anales de la Sociedad Cientifica Argentina 93:119-146.

Brues, C.T. (1907). New chalcid-flies from Cape Colony. Bulletin of the Wisconsin Natural History Society 5(1): 46-53.

Cameron, P. (1883). Descriptions of new genera and species of Hymenoptera. Transactions of the Entomological Society of London 1883:187-197.

Crawford, J. C. (1912). Descriptions of new Hymenoptera No. 4. proc. U.S. Natn. Mus. 42: 1-10.

Dharmadhikari, P.R., G. Rameseshiah \& P.D. Achan (1985). Survey of Lymantria obfuscata and its natural enemies in India. Entomophaga $30(4): 403$

Dalla Torre, K.w. von, (1898). Catalogus Hymenopterorum hukusque descriptorum systematicus et synonymicus V. Chalcididae et Proctotrupidae, 598pp. Lepzig.

De Santis, L. (1952). Calcidoideos Argentinos, nuevos y conocidos (Hymenoptera). Revista de la Sociedad Entomológica Argentina 15:267268. 


\section{Key to species of Anastatus of Indian Subcontinent (Based on females)}

1. F1 distinctly longer than clava (Fig. 22); propodeum (Boucek 1979, Fig. 18) with compatatively long plical region, the foramen not extended to anterior margin of propodeum; forewing macropterous, extensively infuscate but with paler band along length of MV ....................... * Anastatus (Cladanastatus) madagascariensis Bouček F1 shorter or rarely about as long as clava; propodeum with foramen incurved to V-shaped anteromedial emargination of anterior margin; forewing brachypterous or macropterous, but if macropterous then almost always infuscate with hyaline cross band or anterior and posterior spots behind MV (Figs. 20, 15, 30) Anastatus (Anastatus) Motschulsky

2. Forewing shorter than metasoma (when meassured separately on the same scale) Forewing at least as long as metasoma (when meassured separately on the same scale) .......................... 6

3. $\quad$ Forewing extending well beyond T1; infuscated and with 2 oblong whitish (translucent) spots near tip; frons coppery; pronotum metallic green; mesoscutum flat ovate, velvety black; metasoma sub-violaceous posteriorly with tip greenish, Sri Lanka ................................................................................... ${ }^{*}$ echidna (Motschulsky) Forewing not as above, shorter, usually not extending beyond T1; other characters partly or completely different from above

4. SAC orange yellow, apical quarter to third of forewing (Fig. 36) infumated; F2 longest funicular segment; MS $0.55 x \mathrm{EH}$; MLM almost flat, weakly reticulate; acropleuron weakly and longitudinally striate-reticulate; metasoma $1.75 \mathrm{x}$ as long as wide; mesosoma yellowish brown; IAA with purple tint; head metallic green with bronzy tint on frons libratus Narendran, sp. nov. SAC dark brown; forewing with infumation (Figs. 24, 64) longer than above; other characters partly or completely different

5. MLM pale brownish yellow without metallic refringence, $0.57 x$ length of mesoscutum; clava not pointed (Fig. 62); scape (Fig. 62) slightly curved and almost as long as combined length of F1-F3; T7 reddish brown; frons black with coppery refringence and other regions of head metallic green; acropleuron pale yellowish brown ............

rufopostumus Narendran, sp. nov. MLM dark with slight metallic green refringence, $0.71 x$ length of mesoscutum; clava (Fig. 23) somewhat pointed; scape (Fig. 23) distinctly shorter than combined length of F1-F3; T7 dark brown or black; frons and other regions of head metallic green; acropleuron darker than above

hayati Narendran, sp. nov.

6. Forewing (from the original insertion below tegula ) not reaching apex of metasoma, at most reaching $0.86 x$ length of metasoma

Forewing reaching or exceeding apex of metasoma

7. Head and mesosoma yellow; clava 2x as long as wide (Fig. 6); legs yellow; forewing (Fig. 8) without a separate pale brown patch near parastigma besides 2 hyaline patches below MV......

alaredactus Narendran, sp. nov. Head and mesosoma black without metallic green or blue refringence; clava (Fig. 56) a little more than 2.5x as long as wide;legs dark bown with paler tips; forewing (Fig. 57) with a pale brown patch below parastigma besides two hyaline patches below MV

quilonicus Narendran, sp. nov.

8. Forewing with only a circular infumate region behind STV and PMV and with a paler spot anteriorly in the infumation but all setae brownish(lacks a complete cross line or two separate spots) ............... ${ }^{*}$ mantoidae Motschulsky Fore wing not as above, always with a cross line or two separate spots ............................................. 9

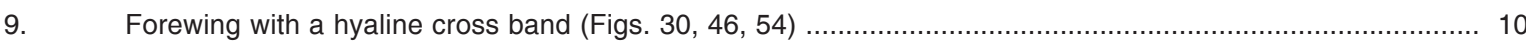
Forewing with two large hyaline spots or oval patches below MV, each spot clearly separated by infumated

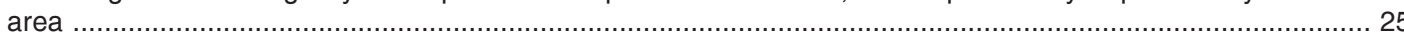

10. Hyaline band of forewing with more or less straight margins (Figs. 2, 11), the band commencing from about

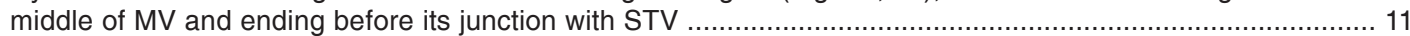

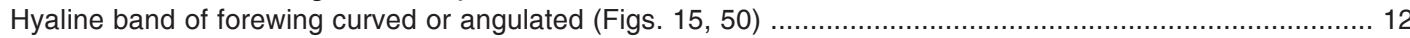

11. Scape, pedicel, anellus, and F1-F4 brownish yellow, but rest of antenna black (Fig. 1); MLM metallic green with base and 3 longitudinal strips pale yellow; forewing (Fig. 2) infumation weak, pale brown

absonus Narendran, sp. nov.

Scape pale brownish yellow and rest of antenna dark brown (Fig. 10), MLM black with metallic green refringence; forewing (Fig. 11) infumation stronger, dark brown ...................................... bangalorensis Mani \& Kurian

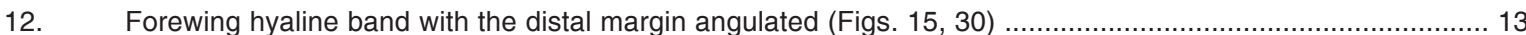

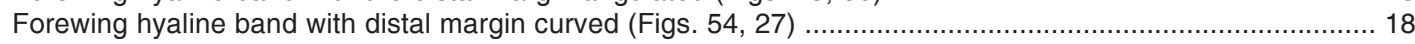

13. F1 almost $2 x$ as long as pedicel, about as long as clava, MV subequal to STV; head green, face metallic red; MLM bronzy; SAC bronzy; metasoma aeneous with a white cross band near T1; pedicel green; basal funicular segments aeneous colemani Crawford F1 shorter than above; other characters partly or completely different 14

14. All funicular segments longer than wide (Fig. 66); mesosoma brownish yellow, head metallic green with coppery refringence, STV 0.50x PMV; ................................................................................. tenuipes Boliver (part) Not all funicular segments longer than wide, at least F6 and F7 wider than long .............................................15

15. Forewing hyaline band extending to junction of MV and STV (Fig. 50) .................................................. 16

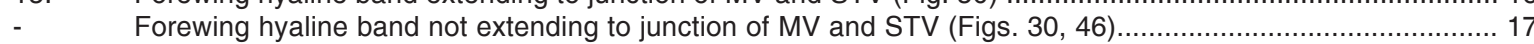

16. F1 and F2 shorter than pedicel; clava subequal to length of scape (Fig. 48); acropleuron granulate-reticulate; 
head dark brown with bronze refringence; mesoscutum and SAC dark brown with metallic bronze refringence on MLM and on SAC .......................................................................... operosus Narendran, sp. nov. F1 and F2 distinctly longer than pedicel; clava shorter than scape (Fig. 15); acropleuron longitudinally striate; head black with slight bronze and metallic green refringence; mesoscutum and SAC black with metallic green refringence

cuspidiatus Narendran, sp. nov.

17. Antenna pale yellowish brown through F4, and F5 to clava black; mesosoma with pronotum, anterior part of mesoscutum, prepectus and acropleuron pale yellow, and remaining part of mesoscutum dark metallic green; forewing cross band broadest at posterior margin of wing (Fig. 46), broader than length of PMV; metasoma pale yellow with apical half of T1 and T2 completely pale white ab(Fig. 47) ............. ochirasis Narendran, sp. nov. Antenna black except scape pale brownish yellow; mesosoma mostly black except pronotum and prepectus pale brownish yellow; forewing (Fig. 30) cross band not broader than PMV; metasoma black with apical part of $\mathrm{T} 1$ and T2 completelypalewhitish yellow

latheefi Narendran, sp. nov.

18. Fore femur with a denticle at distal third on ventral margin; body dark brown to black, in part metallic; scape $2 x$ as long as clava .......................................................... ramakrishnai (Mani) (= dentatus Narayanan et al.) Fore femur without denticle, other characters partly or completely different .

19

19. All funicular segments longer than wide (Fig. 66), SAC longitudinally striate-reticulate [body brownish yellow; head metallic green with coppery refringence; anellus pale yellow; STV 0.50x PMV........tenuipesBoliver (part)

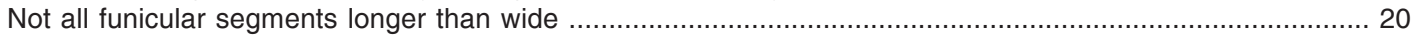

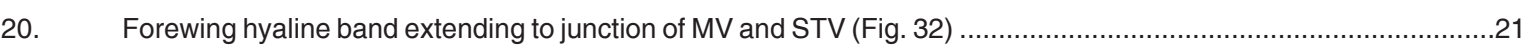

- $\quad$ Forewing hyaline band not extending to junction of MV and STV (Fig. 27) ..............................................22

21. Mesonotum metallic bluish green with purplish refringence except scutellum with a coppery tinge; scutellaraxillar complex longitudinally striate; MV a little less than 2x as long as SMV ................. * kashmirensis Mathur Body dark brown, but MLM and SAC dark metallic green; scutellar-axillar complex reticulate-punctate; MV almost equal to (38:40) length of SMV .............................................................................. leithi (Walker)

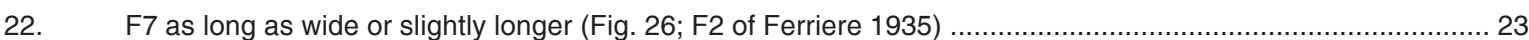

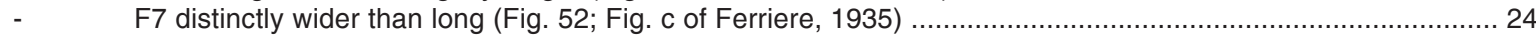

23. F7 as long as wide; metasoma shorter than mesosoma; midtibial spur a little longer than basitarsus of midleg; body dark with metallic green or bluish green and purple refringence ................................... dasyni Ferriere F7 slightly longer than wide; metasoma a little longer than mesosoma; Midtibial spur not longer than basitarsus of midleg; body bronzy black with Metallic bronzy blue, deep blue, bluish violetand dull purple blue refringence In different parts Japonicus Ashmead

24. MLM yellowish brown without metallic refringence on LLM; metasoma more than $2 x$ its width; scape distinctly shorter than $5 x$ pedicel length; head width in dorsal view distictly less than $3 x$ its length; MLM length distinctly less than $0.6 x$ length of mesoscutum ..................................................... phaeonotus Narendran sp. nov. MLM dark with metallic green refringence; metasoma distinctly shorter than $2 x$ its width; scape not al all shorter than $5 x$ length of pedicel; head width in dorsal view not less than $3 x$ its length; MLM longer than 0.6x length of mesoscutum ${ }^{*}$ bifasciatus (Geoffroy)

25. Forewing with hyaline patch below MV extending junction of MV and STV ......................................... 26

- $\quad$ Forewing with hyaline patch below MV not extending to junction of MV and STV ................................... 27

26. Pedicel shorter than F1; F1 to F3 successively longer; clava as long as combined length of F5-F7; metasoma as long as mesosoma; MLM, LLM, area between LLM and beyond MLM, SCA, metanotum and propodeum with dark metallic green refringence ..................................... acherontiae Narayanan, Subba Rao \& Ramachandra Rao Pedicel as long as or longer F1; F1 to F3 subequal in length; clava shorter or rarely as long as combined length of F5-F7; metasoma distinctly longer than mesosoma; [MLM dark brown with deep bluish violet refringence, axillae bronzy, and scutellum with metallic purple refringence ..................................... amarus (Subba Rao)

27. MV about as long as STV or shorter than STV .... ...28

- $\quad$ MV distinctly longer than SMV (52: 48); mesoscutum yellowish brown with MLM and concave area behind MLM black with metallic green refringence; eyes without pubescence .................... mohanae Narendran, sp. nov.

28. Clava as long as preceding 3 funicular segments combined; scape $3 x$ as long as Pedicel; mesosoma with metallic bluish green refringence............................................................. Yasumatsui Shafee Clava distinctly shorter than preceding two funicular segments combined; scape $6 x$ or a little over $6 x$ as long as pedicel; mesosoma with pronotum yellow (except black spiracular border) yellow, mesopleuron redddish brown; mesoscutum dark with metallic refringence donius Narendran sp. nov.

Names with an asterisk indicate no material of the species was examined and the differential features provided are taken from previous descriptions and publications. 
De Santis, L. (1960). Anotaciones sobre caldicoideos Argentinos. II Revista de la Facultad de Agronomía de La Plata (3) 36(2): 109-119.

De Santis, L. (1980). In: De santis, L. J. A. V. S. De Regalia, M. S. L. De Silva, M. Del Carman, and C. De Larramendi, 1980. Identification de los enemiges natinales de la vinchuca. Medicina 9Buenos Aires), 40(Supl. I): 197-206.

De Staphani, T. (1898). Miscelanea entomologica sicula. Naturalista Siciliano (2): 2: 250-257.

Erdös, J. (1946). Genera nove et species nova Chalcidoidarus (Hym.) Annales Historico-Naturales Musei Nationalis Hungarici 39: 131-165

Erdös, J. (1957) Miscellanea chalcidologica hungarica. Annales HistoricoNaturales Musei Nationalis Hungarici (Series Nova) 8: 347-374.

Ferrière, C. (1930). On some egg parasites from Africa. Bulletin of Entomological Research 21(1): 33.

Ferrière, C. (1935). Notes on some bred exotic Eupelmidae (Hym. Chalc.) Stylops 4: 145-153.

Ferrière, C. (1938). Eupelmides exotiques (Hymenopt. Chalcididae). Annales de la Société Entomologique de France 107: 25-72.

Fonscolombe, E.L.J.H. (1832). Monographia chalciditum galloprovinciae circa aquas degentum. Annales des Sciences Naturelles (1) (Zoologie) 26: 273-307.

Forster, A, 1860. Eine centurie neuer Hymenoptereu. Verhandlungen, Bonn, $17 \mathrm{pp}$.

Gibson, G.A.P. (1995). Parasitic Wasps of the Subfamily Eupelminae: Classification and revision of World genera (Hymenoptera: Chalcidoidea: Eupelmidae). Memoirs of Entomology, International Canada, $421 \mathrm{pp}$.

Girault, A.A. (1911) [88]. IX New chalcidoid genera and speies from Paraguay. In: Strand E. 1911. Beitrage zur Kenntnis der Hymenopteren fauna von Paraguay auf Grund de Sammlungen und Beobachtungen von Prof. J.D. Anistis. Zoologische Jahrbïcher, Abteilung fiir Systematik 31:395-396.

Girault, A.A. (1913) [175]. New genera and species of chalcidoid Hymenoptera in the South Australia Museum, Adelaide. Transactions of the Royal Society of South Australia 37:67-115.

Girault, A.A. (1915) [238]. Australian Hymenoptera Chalcidoidea VII. The family Encyrtidae with descriptions of new genera and species. Memoirs of the Queensland Museum 4 pp. 1-184.

Graham, M.W.R. de V. (1992). Hymenoptera collections of Boyer de Fonscolombe, with an account of his work and a description of the natural features of his estate. Journal of Natural History 26: 10891111.

Hayat, M. (1975). Some Indian species of Anastatus (Hymenoptera: Chalcidoidea: Eupelmidae). Oriental Insects 9: 261-271.

He, J.X., F. Zhang, J.M. Zhang \& C. Luo (2001). Effect of releasing Anastatus uaponicus [sic] in the field. Beijing Agricultural Sciences 19(4) pp. 21-23.

Islam, S. \& M. Hayat (1986). Family: Eupelmidae. In: Subbarao, B.R. \& M. Hayat. The Chalcidoidea (Insecta: Hymenoptera) of India and the Adjacent Countries. Oriental Insects 20: 1-430.

Mani, M.S. (1935). New Indian Chalcidoidea (Parasitic Hymenoptera) of cockroach from India. Records of the Indian Museum 37: 241-258.

Mani, M.S. (1936). A new encyrtid parasite (Chalcidoidea: Hymenoptera) of cockroach from India. Records of the Indian Museum 38: 131-132.

Mani, M.S. (1938). Catalogue of Indian Insects Part 23 - Chalcidoidea. Government of India, Delhi, 170pp.

Mani, M.S. (1989). The Fauna of India and Adjacent Countries, Chalcidoidea (Hymenoptera) Part II \& I. Zoological Survey of India, Calcutta, $1633 \mathrm{pp}$.

Mani, M.S. \& C. Kurian (1953). Descriptions and records of chalcids from India. Indian Journal of Entomology 15(1): 1-22.

Masi, L. (1917). Chalcididae of the Seychelles islands. (With an appendix by J.J. Kieffer.) Novitates Zoologicae 24: 162-163.

Masi, L. (1919). Chalcididi del Giglio. Anali delmuseo Civico di storia Naturale di Genova 48: 277-337.

Masoodi, M.A., A.R. Trali, A.M. Bhat, R.K. Tikoo \& R.K. Nehru (1986). Incidence of parasites of Lymantria obfuscata (Lymantriidae: Lepidoptera) in Kashmir. Entomophaga 31(4): 401-404.

Mathur, R.N. (1956). A new species of Anastatus Motschulsky (Chalcidoidea: Eupelmidae) from Kashmir. Procedings of the Royal Entomological Society of London (B) 25: 93-97.

Mehra, B.P. (1966). Studies on the egg-parasites of Tessaratoma javanica Thunberg (Hemiptera: Pentatomidae), with special reference to
Anastatus colemani Crawford (Hymenoptera: Eupelmidae). Indian Journal of Entomology 28(2): 241-249.

Motschulsky, V. de (1859). Insectes des Indes Orientales, et de contrées analogues (2de serie). Études Entomologiques 8: 25-118.

Motschulsky, V. de (1863). Essai d'un catalogue des insectes de l'Ile Ceylon (Suite). Byulleten' Moskovskogo Obshchestva Ispytateley Prirody (Otdel Biologicheskiy) 36(3): 1-153

Narayanan, E. S., B.R. Subba Rao \& M.R. Rao (1960). Some new species of Chalcids from India. Proceedings of the National Institute of Sciences of India (B) 26: 168-175

Narendran, T.C. (2001). Parasitic Hymenoptera and Biological control. Palani Paramount Publications, Palani, 191pp.

Noyes, J.S. (2003). Universal Chalcidoidea Database. World Wide Web electronic publication. [Hyperlink "http://www.nhm.ac.uk/ entomology/chalcidoids".

Risbec, J. (1951). 1. Les Chalcidoides de l'Afrique occidentale française Mémoires de l'Institute Français d'Afrique Noire, Ifan-Dakar 13: 274.

Risbec, J. (1952). Contribution a l'etudedes Chalcidoides de Madagascar. Mémoires de l'Institut Scientifique de Madagascar (E) 2:1-449

Risbec, J. (1955). Hyménoptères parasites du Cameroun. Bulletin de l'Institut Français d'Afrique Noire (A) 17(1): 191-266.

Rondani, C. (1877). Vesparia parassita non vel minus cognita observata et descripta. Bullettino Della Società Entomologica Italiana 9(2): 166213 + plate IIIa-Via.

Ruschka, F. (1921). Chalcididenstudien I. Verhandlungen der ZoologischBotanischen Gesellschaft in Wien 70: 265.

Shafee, S.A. (1973). Two new species of Eupelmidae from Indi (Hymenoptera: Chalcidoidea). Acta Zoológica Lilloana 30: 135-140.

Subba Rao, B.R. (1957). Some new species of Indian Hymenoptera. Procedings of the Indian Academy of Science (B) 46: 376-390.

Swezey, O.H. (1946). Insects of Guam, II. Notes on some Chalcidoidea Bulletin of the Bernice Pauahi Bishop Museum, Honolulu 189: 211-219.

Thuróczy, C. (1992). The types of Chalcidoidea described by Hungarian authors, preserved in the Hungarian Natural History Museum. Folia Entomologica Hungarica 52:140

Walker, F. (1872). Notes on Chalcididae Part V- Encyrtidae, Myinidae, Eupelmidae, Cleonymidae, Spangiidae, Ormyridae, Encyrtidae, Encyrtidae. Pp55-70, London.

Walsh, B.D. \& C.V. Riley (1869). The joint-worm (Isosoma hordei, Harris). American Entomologist 1: 156.

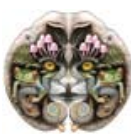

